

\title{
CATALYSIS STUDIES
}

\author{
by \\ T. N. Taylor and W. P. E11is
}

This report wots wote

sponsored by the srepared at an sccuunt of wonk

Unted States nor the States Govemment. Neither the

Energy, nor any of the United Sines Depertment of contractors, subcontheir employees, nor any of their contractors, subcontractors, of their emplayy of their any warranty, express or implied, or amplayeres, makes fiability of respontibilily for the accuncy, completenets or usefulnes of any information, apparalus, product or infringe priveted, of mpresents that its une would not infinge privitely a wned ritho.

\begin{abstract}
The New Research Initiatives Program (NRIP) project on catalysis in Los Alamos Scientific Laboratory (LASL) Group CMB-3 has made significant progress towards performing the first basic in situ experimental studies of heterogeneous catalysis on solid compound surfaces in a LEED-Auger system. To further understand the surface crystallography of a possible catalyst compound, LEED-Auger measurements were made on $\mathrm{UO}_{2}(-100)$ vicinal surfaces. These ( 100) vicinal surfaces were shown to decompose irreversibly into lower index facets, including prominent (100) facets, at temperatures below those needed for creation of lowest index faceting on ( 111) vicinal surfaces. LEED examination of fully faceted surfaces from both types of $\mathrm{UO}_{2}$ vicinal cuts did not show evidence of cyclopropane or propene chemisorption. The existing LEED-Auger system was modified to allow catalytic reactions at $\leqslant 10^{-3}$ torr. A sample holder, specifically designed for catalysis measurements in the modified system, was tested while examining single crystals of $\mathrm{CoO}$ and $\mathrm{Cr}_{2} \mathrm{O}_{3}$. Extensive LEED-Auger measurements were made on $\mathrm{CoO}$ in vacuo and in the presence of light hydrocarhons and alcohols plus $\mathrm{H}_{2} \mathrm{O}$, NO, and $\mathrm{NH}_{3}$. No chemisorptive bshavior was observed except with $\mathrm{H}_{2} \mathrm{O}$ in the presence of the alectron beam. Although only examined brief $1 y$, the $\mathrm{Cr}_{2} \mathrm{O}_{3}$ was remarkable for the sharp LEED features obtained prior to any surface treatment in the vacuum system.
\end{abstract}

\section{INTRODUCTION}

The New Research Initiatives Program (NRIP) project on catalysis in Group CMB- 8 has made substantial progress towards performing the first basic in sittu 
experimental studies of heterogeneous catalysis on solid compound surfaces in a LEED-Auger system.

During the past 15 years a number of valuable techniques have been developed which permit detailed experimental analysis of the solid-gas interface. These analytical. method's employ state-of-the-art vacuum technology to create an environment appropriate for surface examination via electrons, lons, photons, or other atomic scale probes. Some of these surface tools give informition on the surface constituents or crystallography while others measure the electronic properties of the surface.

Group $\mathrm{CMB}-8$ has been active in surface characterization through use of low energy electron diffraction (LEED), ${ }^{1}$ Auger electron spectroscopy (AES), ${ }^{2}$ ion scattering spectroscopy (ISS), ${ }^{3}$ and photoemission spectroscopy (PES). ${ }^{4}$ Where single crystal material is under study, LEED is used for surface crystallographic measurements of the substrate and adsorbed foreign species. AES is primarily utilized to determine surface composition by analysis of well-defined Auger electron energies found in the secondary electron energy spectrum. ISS seeks the same type of information by energy measurement of ions scattered from a surface. In addition to composition measurements, PES records surface electronic properties by energy analysis of photoemitted electrons. The NRIP project on catalysis in Group CMB-8 has focussed on using a LEED-Auger system to characterize surface parameters important in heterogeneous catalysis on various solid compounds.

A substantial amount of basic research in surface characterization of catalysts has and is being done at the Lawrence Berkeley Laboratory by Prof. Gabor A. Somorjai and his colleagues. Most of this effort has been directed towards understanding catalysis on single-crystal configurations of clean platinum. 5 Their research has correlated catalytic activity with the presence of surface defects in the form of simple steps and steps with kinks. To date ${ }^{6}$ they have shown that simple steps are responsible for $\mathrm{H}-\mathrm{H}$ and $\mathrm{C}-\mathrm{H}$ bond breaking while kink sites have the added ability of breaking $\mathrm{C}-\mathrm{C}$ bonds. The experinentation has produced information on carbon overlayer structures, or template structures, that are a factor in controlling catalytic activity. Their work has detailed the stability and restructuring properties of various high-index Pt surfaces in the presence of oxygen or carbon. 8 With the exception of a few stable surfaces, most high-index planes were altered by changing the environment. Extrapolating these results to dispersed particles of $P t$, the stable surfaces were thought to 
be the dominant catalyst surface structures in hydrocarbon catalysis. Most of the research in Somorjai's group has been accomplished using LEED and AES supported by mass spectrometer analysis of catalytic reaction products at pressures $\lesssim 10^{-3}$ torr. At these pressures the ultra-high vacuum system housing the experimental probes serves as the catalytic reaction vessel. In the last several years, Somorjai has modified or built several syctems which incorporate both ultra-high vacuum and atmospheric pressure features. ${ }^{9}, 10$ sucis a state-of-theart system allows ultra-high vacuum characterization of a catalyst surface (i.e.. AES, LEED, or thermal desorption) before and after running a catalytic reaction at atmospheric pressure. This apparatus has teen used to analyze the hydrocarbon products formed by $\mathrm{CO}-\mathrm{H}_{2}$ and $\mathrm{CO}_{2}-\mathrm{H}_{2}$, reactions over polycrystalline rhodium at 700 torr. ${ }^{11}$

In a study of the catalytic oxidation of $\mathrm{CO}$ on stepped platinum surfaces, Hopster et al. ${ }^{12}$ have reported the interrelation of step density and $\mathrm{O}_{2} / \mathrm{CO}$ pressure ratio. Using LEED and AES measurements at pressures $\leqslant 10^{-6}$ torr, they found values for co reaction probability, oxygen coverage, and oxygen sticking coefficient. Their results indicate that surface defects in the form of steps may increase or decrease the catalytic oxidation of co relative to a (111) platinum surface depending on the reaction conditions. Additionally, they have shown that the oxygen sticking coefficient for coverages between 0.02 and 0.10 monolayer increases exponentially with step concentration - requiring a nonlocal explanation for adsorption on a stepped surface.

The CMB- 8 catalysis project on solid compounds parallels the ideas and techniques behind Somorjai's catalysis research program on metals. However, the effort has concentrated strictly on in situ catalysis measurements at $\leqslant 10^{-3}$ torr in a modified LEED-Auger system. Catalytic properties on solid compounds have not previously been examined in this manner as the difficulty of obtaining easily interpretable results far exceeds that for similar measurements on a pure metal. This is a consequence of the addition of a second major bulk constituent where, undoubtedly, the thermodynamic and electronic properties of the compound in the near surface region differ markedly from those of the bulk.

In the past Group $\mathrm{CMB}-8$ has been involved in surface measurements on actinide elements, their alloys, and compounds. A considerable effort has been expended determining the surface composition and crystallography of single crystal $\mathrm{UO}_{2}$. Through use of LEED, Ellis and Schwoebel ${ }^{13}$ demonstrated that the $\mathrm{VO}_{2}(553)$ surface could be ordered to form a repeating sequence of steps of minimum height. 
In this first analysis of diffraction produced by a stepped surface, they suggested that such defect surface structurea be examined for catalytic effects. The NRIP project on catalysis represents the initial attempt to pursue this suggestion in Group CMB-8. Since the pioneering experiment on stepped surfaces, ElJ.is has used LEED to analyze other $\mathrm{UO}_{2}(\sim 111)$ vicinal surfaces of more complex crystallographic content. ${ }^{14}$ Analogous information from $\mathrm{UO}_{2}$ single-crystal surface models has been gained through application of laser transforms. ${ }^{2}, 15,16$ Because such a vast amount of information on step structured surfaces of single crystal $\mathrm{UO}_{2}$ is available in $\mathrm{CMB}-8$, this material was a natural selection as one of the compounds to be included in this project. In addition, because of the relevance of $3 \mathrm{~d}$ oxides to commercial processes, single crystal materials of cobaltous oxide $(\mathrm{COO})$ and chromia $\left(\mathrm{Cr}_{2} \mathrm{O}_{3}\right)$ were incorporated in the study.

The NRIP catalysis studies program in CMB- 8 has developed in three stages. First, to further augment understanding of possible catalyst surfaces, an examination of $\mathrm{UO}_{2}(\sim 100)$ vicinal surfaces was undertaken in the existing LEED-Auger vacuum system. Second, the LEED-Auger vacuum chamber was modified so that it could be used as a catalytic reaction vessel at pressures $\lesssim 10^{-3}$ torr. Third, single crystal samples of $\mathrm{UO}_{2}, \mathrm{CoO}$, and $\mathrm{Cr}_{2} \mathrm{O}_{3}$ were examined in the modified LEEDAuger system. The remainder of this report will treat these three stages in some detail.

\section{STUDY OF $\mathrm{UO}_{2}(\sim 100)$ VICINAL SURFACES}

A. Sten Surface Crystallography and Its Measurement

Measurements were made on two types of high-index surfaces vicinal to the $\mathrm{UO}_{2}(100)$ face. In a perfectly ordered condition, these two classes of surfaces consist either of uniform arrangements of simple steps (terrace-ledge array, TL) or of steps with kinks at regular intervals (terrace-ledge-kink array, TLK). The drawings and hard-sphere models of Fig. 1 demonstrate the two types of $\mathrm{NO}_{2}(\sim 100)$ vicinal surfaces. Removing the kink site atoms from the T.T models of Figs. IC and $1 \mathrm{D}$ reduces them to the (711) TL array of Fig. 1A and the (510) TL array of Fig. 1B, respectively. Note that in the hard-sphere models where the oxygen atoms are included, the ledges appear as $\{111\}$ planes for the (711) surface and as $\{110\}$ planes for the (510) surface. If the kink site atoms are included, as shown in Figs. 1C and 1D, the topmost ledges in the TLK arrays exhibit two kinds of possible kink structures. For viewing clarity the outermost oxygen layer has been omitted in both hard-sphere models. Of course, a real surface is 


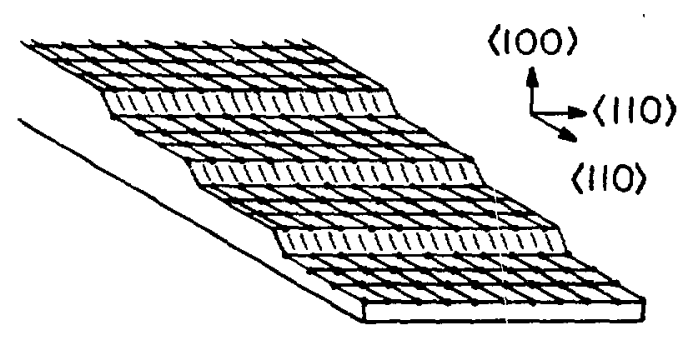

A

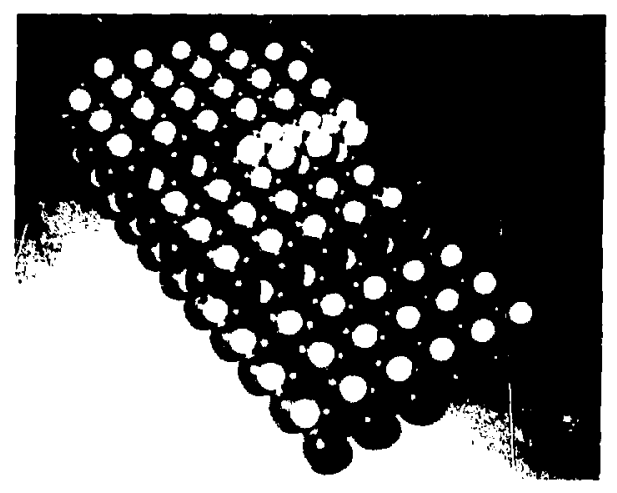

C

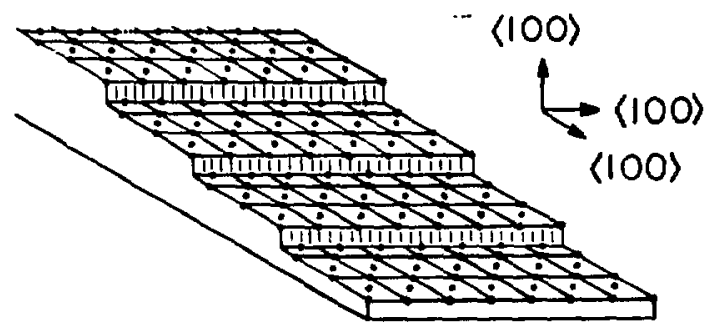

B

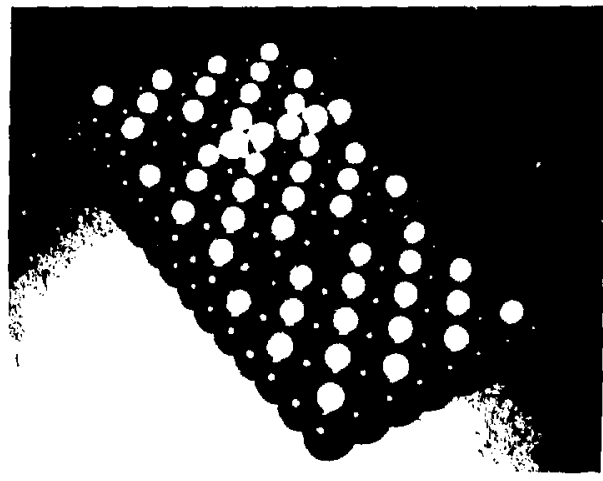

D

Fig. 1

A. Idealized drawing of a $\mathrm{UO}_{2}(711)$ stepped surface. Oxygen atoms have been omitted. Ledges are drawn as $\{111\}$ planes.

B. Idealized drawing of a $\mathrm{UO}_{2}(510)$ stepped surface. Oxygen atoms have been omitted. Ledges are drawn as $\{100\}$ planes.

C. Hard-sphere model showing a possible $\mathrm{UO}_{2}(\sim 100)$ vicinal TLK arrangement produced by adding kink-site atoms to the (711) TL surface. (711) ledges appear as $\{111\}$ planes.

D. Hard-sphere model showing a possible UO $(\sim 11$ ) vicinal TLK arrangement produced by adding kink-site atoms to the (510) TL surface. (510) ledges appear as $\{110\}$ plines.

Large dark spheres are oxygen atoms. Large grey spheres are kjnk-site oxygen atoms. Small white spheres are uranium atoms.

inhomogeneous to the extent that it will statistically contain a number of random deviations or mistakes from such ideal representations. This statistical content is a function of overall surface uniformity, cleanliness, and previous treatment. 
If a monoenergetic beam of electrons is incident on a single-crystal surface, elastic diffraction will result when the difference between the scattered and incident electron wave vectors, $\vec{k}_{f}-\vec{k}_{i}$, where $\left|\vec{k}_{f}\right|=\left|\vec{k}_{i}\right|$, is equal to a surface reciprocal lattice vector. ${ }^{1}$ For a simple one-dimenstonal chain of interatomic spacing "a," diffraction for normal incidence obeys the Bragg condition

$$
a \sin \theta=m \lambda \text {. }
$$

where $\Theta$ is the scattering angle, $\lambda$ is the electron wavelength, and $m$ is an integer. The electron wavelength is given nonrelativistically by

$$
\lambda=(150 / \mathrm{eV})^{1 / 2}
$$

where $\mathrm{PV}$ is the electron's kinetic energy in electron volts. The term low-energy electron diffraction or its acronym LEED is applied to an electron energy range between 10 and $500 \mathrm{eV}$. LEED readily yields information on surface symetry and interatomic spacings. However, determination of exact atomic locations on the surface via LEED data is inuch more djfficult and the solution of this problem is still the object of much attention, 17

A typical LEED experimental setup is schematically represented by Fig. 2. The electron gun, located within the LEED optics, generates a focussed beam of electrons of approximately $0.5-\mathrm{eV}$ half-width. The focussed electrons travel down the drift tube and strike the sample at ground potential. Electrons inelastically scattered into the LEED optics are rejected by two retarding grids so that only the back diffracted elastic electrons are imaged by the fluorescent screen subtending a solid angle behind the drift tube. Thus, for example, a clean, well-ordered (100) fcc single-crystal surface will produce a fourfold spot pattern on the screen that is easily seen by an observer through the vacuum viewport. The substrate spots in the diffraction pattern are indexed using integers. In the inelastic or Auger mode of operation, the two inner grids are modulated and ramped electronically while the fluorescent screen serves as the collector for a phase sensitive detection configuration used to measure the electron energy spectrum. All surface measurements are usually done under ultrahigh vacuum conditions to preserve the state of the surface during the course of data acquisition. 


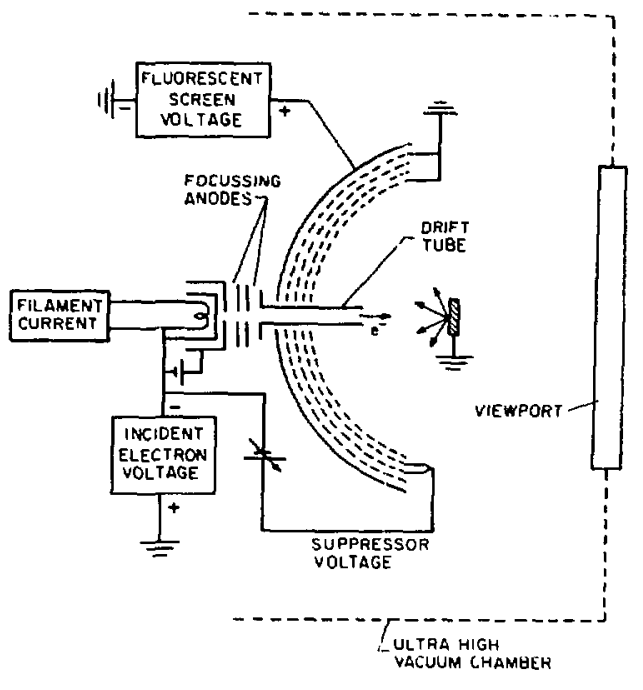

Fig. 2

Schematic representation of LEED gun and electron optics in the elastic mode.
If the surface is comprised of an ordered arrangement of steps, the diffraction features are more complex than those described above. For the two dimensional step model of Fig. 3, the kinematical diffracted intensity obeys the equation

$$
I \alpha\left(\frac{\sin N \delta / 2}{\sin \delta / 2}\right)^{2}\left(\frac{\sin M \gamma / 2}{\sin \gamma / 2}\right)^{2} \text {. }
$$

where $\delta=\Delta \overrightarrow{\mathrm{k}} \cdot \overrightarrow{\mathrm{a}}, \gamma=\Delta \overrightarrow{\mathrm{k}} \cdot[\overrightarrow{\mathrm{d}}+(\mathrm{N}-1) \overrightarrow{\mathrm{a}}+$ $\vec{g}], \Delta \vec{k}=\vec{k}_{f}-\vec{k}_{i},|\vec{a}|$ is the interatomic spacing in each terrace, $N$ is the number of atoms in each terrace, $|\vec{d}|$ is the step height, $|\vec{g}|$ is the displacement between terraces, and $M$ is the number of terraces. ${ }^{13}$ The first

factor describes the diffracticn from each terrace and is simply the grating equation for a one-dimensional chain of scatterers. Each terrace's contribution to the diffracted intensity as a function of scattering angle, $\Theta$, is given by the upper intensity profile of Fig. 3. Equation (1) locates the intensity maxima for this profile. The diffraction from each terrace involves a relatively smal1 number of scattering atoms and, thus, the primary diffraction envelope is quite broad. The second factor in Eq. (3) describes the diffracted intensity from the steps in that the vector $\vec{d}+(\mathrm{N}-1) \vec{a}+\vec{g}$ crosses a step and is in the average plane of the surface. Because a large number of steps, or scattering units, are located within the coherence diameter ${ }^{1}$ of the diffracting electrons, this factor gives narrow primary maxima profiles. The intensity profile from this factor is simply represented by the delta functions of the lower plot in Fig. 3 . Thus, a stepped surface produces extra diffraction features or fractional order spots when compared to the diffraction features from the low index surface. From Eq. one sees that as $\lambda$ is decreased the integral order beams collapse around the specularly reflected (00) beam, which is normal to the terraces. Because the delta functions from the step diffraction collapse around $\theta_{s}$ (twice the angle of incidence to the average surface direction) as $\lambda$ is decreased, the two sets of 

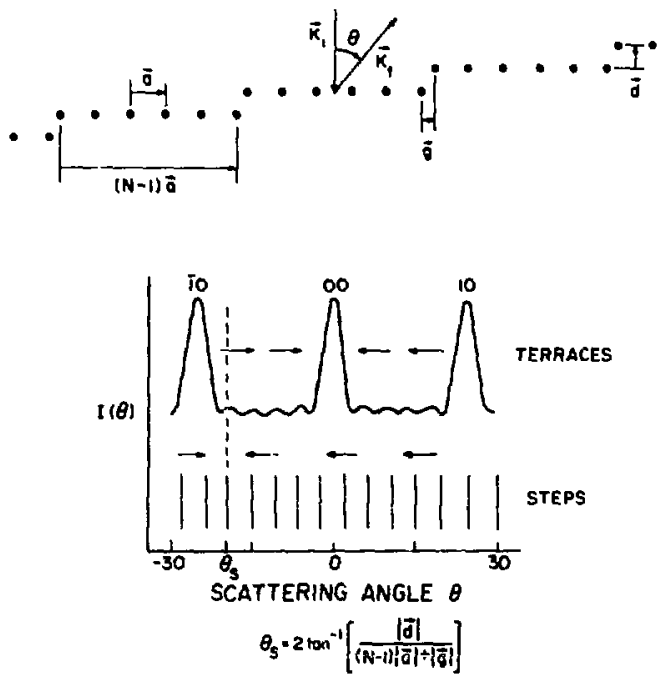

Fig. 3

Two dimensional TL model and the kinematic LEED intensity, $I(\theta)$, from its terraces and steps. I( $\theta)$ is calculated from the terrace and step factors of $\mathrm{Eq}$. (3), taken from Henzler 18 where $N=6$, $|\vec{a}|=3.46 \AA,|\vec{d}|=3.25 \AA,|\overrightarrow{\mathrm{g}}|=1 / 3|\overrightarrow{\mathrm{a}}|$, and $\lambda=1.45 \AA$ (incident energy=71 eV). A doublet voltage condition is indicated near $\theta=0^{\circ}$. Arrows show direction in which diffraction featı.res move as $\lambda$ is decreased. diffraction features move through one another as the energy is changed and give rise to a variety of spot configurations. Two simple diffraction conditions are evident. First, when the maxima of the two factors of Eq. (3) coincide, one intense spot is observed at the location of the low index integral spot. For the (00) terrace spot

$$
V_{o o}=150 s^{2} / 4 d^{2}
$$

where $V_{o o}$ is the incident electron energy and " $s$ " is an integer. Second, a diffraction doublet is observed when two delta functions are symetrically located about a low index maximum, as is the case for $I(\theta)$ near (00) in Fig. 3. The angular separation of the doublets in the vicinity of $\theta=0$ is given by

$$
\Delta \theta=\frac{\lambda}{(\mathrm{N}-1) \mathrm{a}+\mathrm{g}}
$$

These types of simple kinematical calculations include only single scattering events and no electron penetration below the surtace layer. A very complicated dynamical calculation of the scattering which includes multiple events, electron penetration into the solid, and electron attenuation from inelastic events, would be necessary to faithfully reproduce the intensity variation of the diffraction as a function of incident electron energy. While the kinematical calculation gives information on the allowed diffraction features, only a poor first-order approximation is made regarding the diffracted intensities.

In general, the LEED pattern obtained from an ordered array of steps is characterized by a splitting of the integral order spots associated with the terraces forming the steps. Singlets, doublets, and multiplets aligned in a 
direction normal to the average ledge direction may appear as a function of incident energy near any of the integral order spot positfons. Wth increasing energy the diffraction spots from a step array move sn that the pattern as a whole converges toward specular reflection for the high-index surface in question. Determination of the angle relating this specular reflection to that for a known direction allows indexing of the stepped surface. The following work applies these ideas pictorially by photographing LEED patterns from stepped surfaces with variation in incident electron energy. The streak or convergence photo obtained readily lends itself to interpretation using the ideas presented in Fig. 3 .

Kinematical calculation of the diffraction from a three-dimensional (553) surface model has been successfully done by Ellis and Schwoebel. ${ }^{13}$ However, for more complicated surfaces and, to be sure, for those including some disorder, the calculation would involve a great deal of time. As previously mentioned, optical simulation of such complex systems has been success fully employed by Ellis $14,15,16$ to gain some general insights into their diffraction features. As described by Ellis ${ }^{14}$ for both ordered and disordered stepped $\mathrm{UO}_{2}$ surfaces, the topmost uranium atons are projected onto a low index plane to form a two-dimensional array. A small grating is made by photographing the array after which laser light is passed through the grating and the diffraction then imaged on a screen. Although the voltage dependence of the diffracted beam positions and intensities is lost, the main features of the electron diffraction are contained in the usalogous optical simulation. Variation of the electron energy should produce the diffraction features seen in the analogous uptical pattern. The grating used for optical simulation of a UO2 TLK surface, vicinal to the (100) plane, is shown in Fig. 4A. The optical diffraction pattern from this grating is reproduced in Fig. 4B. Note that the direction defined by the intense doublets is normal to the average ledge direction indicated on the grating. E11is 14 has shown that the addition of TLK disorder to the two-dimensional surface model increases the background and washes out all but the most intense diffraction features.

B. Samples and Apparatus

f. four grid, fluorescent display LEED-Auger system was used to study three samples. Two of the samples, cut to expose (100) vicinal faces, were being examined for the first time. The third had been previously used in the $\operatorname{LO}_{2}(\sim 111)$ vicinal experiment. 14 The $\mathrm{UO}_{2}(\sim 100)$ vicinal faces were cut at a polar angle, $\beta$, 


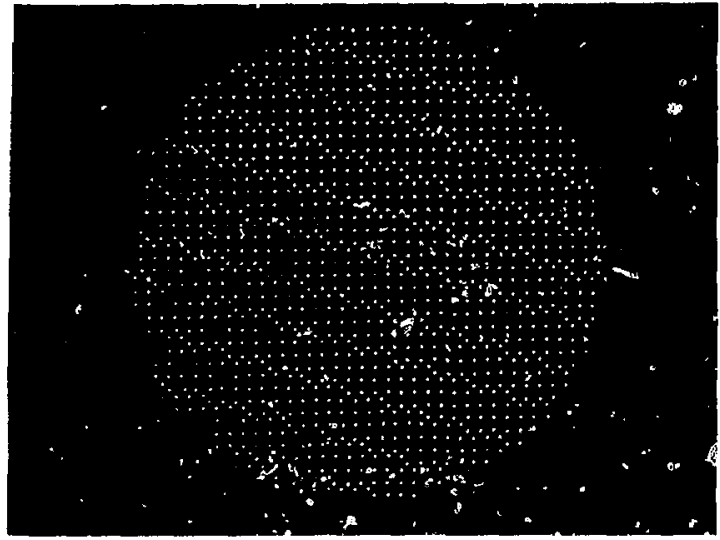

A

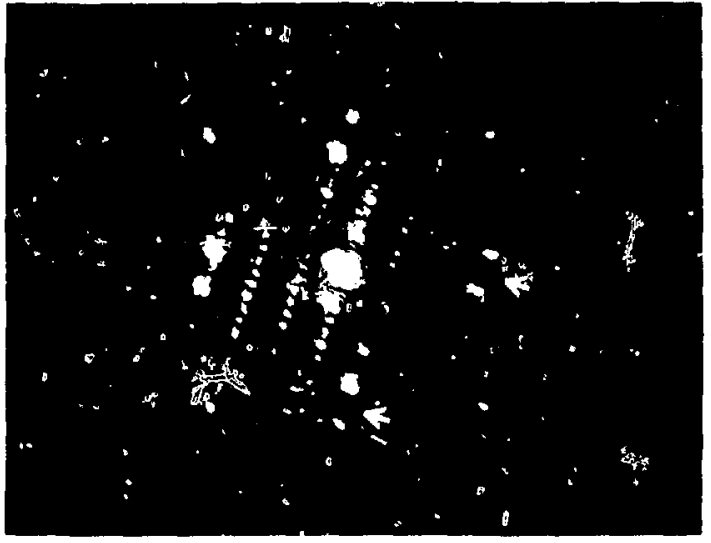

B

Fig. 4

A. Optical grating used to simulate a UC2 TLK surface vicinal to the (100) plane.

B. Optical diffraction pattern produced by the grating in (A). Arrows indicate $i$ ti.ense doublet features near lowest order terrace beams.

of $11.5^{\circ}$ from the (1C.0) surface and at the azimathal angles, $\alpha$, indicated in Fig. 5. As noted in the table of Fig. 5, two of these surfaces are very nearly equivalent to (711) and (510) planes. If the uraniun atoms in the topmost layers of well-ordered (711) and (510) stepped surfaces are projected onto the (100) plane, arrays like those of Figs. $6 \mathrm{~A}$ an. $6 \mathrm{C}$ are obtained. Similar projections. of well ordered TLK surfaces $E$ and $F$, shown in Figs. 6B and 6D, give a clear picture oi the sequence of kinks present in each high-index face. These latter two projections show an average ledge direction of $\langle 210\rangle$ and $\langle 510\rangle$ for surfaces $E$ and $F$, respectively. Sample one contained three distinct faces: (711), E, and a (100) reference. Sample two contained four distinct faces: (711), (510), $F$, and a (100) reference. The third sample was composed of a (111) reference face and three TLK faces (A, B, D) cut at similar polar angles $\left(14.5^{\circ}, 13^{\circ}, 13^{\circ}\right.$ ) from the (100) face, and having azimuthal angles $\left(30^{\circ}, 16^{\circ}, 47^{\circ}\right)$ about the [111] pole that spanned the $60^{\circ}$ angle measured from the $\langle 553\rangle$ to the $\langle 311\rangle$ pole projection on the (111) plane. (S_e Ref. 14 for more crystallographic detai1). This last sample was repolished by hand and undoubtedly the faces were not as planar or uniform as when first examined.

After cutting and coarse girinding to give the above sample configurations, the various surfaces were fine polished in $1-\mu$ Struers diamond paste. The remaining mechanically disturbed layers were removed by etching at $285^{\circ} \mathrm{C}$ in $\mathrm{HF}$ vapcr, followed by 1.5 -minute immersion in a $0.2 \mathrm{M}$-solution of $\mathrm{HNO}_{3}$. Each sample 10 


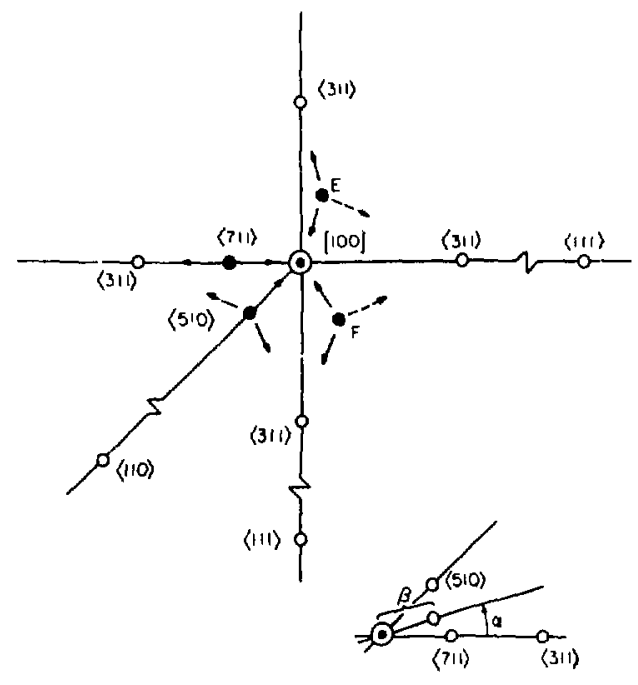

\begin{tabular}{|c|c|c|c|c|c|c|c|}
\hline FACE & $(100)$ & $\langle(11)$ & $\langle 5(0)$ & $E$ & $F$ & $\langle 311\rangle$ & $\langle 410\rangle$ \\
\hline$|a|^{\circ}$ & - & 0 & 45 & 184 & 337 & 0 & 45 \\
\hline$\beta^{\circ}$ & \pm 1 & 114 & 113 & 115 & 115 & 252 & 140 \\
\hline
\end{tabular}

Fig. 5

Crystallographic pole diagram showing the five suifaces examined, where $\alpha$ and $\beta$ are the azimuthal and polar angles defined by the inset. The arrows pointing to [100] and $\langle 311\rangle$ from $\langle 711\rangle$, $\langle 510\rangle, E$, and $F$ indicate the final facet configurations as discussed in the test.

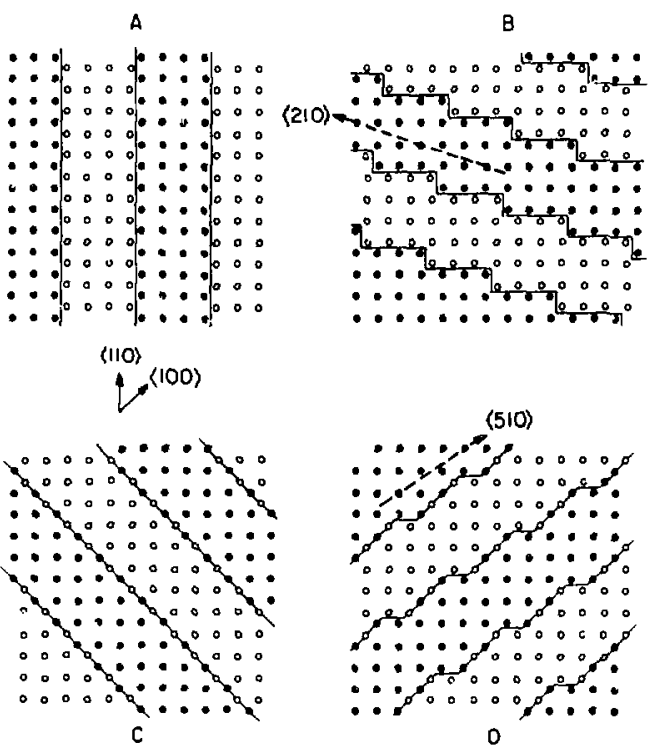

Fig. 6

Projections of various stepped $\mathrm{UO}_{2}$ surfaces onto the (100) plane. Successive (100) terraces are alternately dots (.) and circles (o). Only the topmost uranium atoms have been projected.
A. TL, (711)
B. TLK, surface E
c. TL, (510)
D. TLK, surface $F$

was mounted on a stainless steel holder by means of a $\mathrm{P}$. mesh and placec. in the vacuum chamber immediately after the final chemical etching. All face orientations were verified within $\pm 1^{\circ}$ by using standard Laue $x$-ray techniques.

The holder-plus-sample assembly could be heated in vacuum by an arrangement of cathode heaters suspended within the holder. Temperature measurements were made via a Pt - 10\%Rh-Pt thermocouple spot welded to the holder. Unknown thermal contact between the sample and holder limited the accuracy of sample temperature determination to no betier than $\sim 50^{\circ} \mathrm{C}$. Prior to experimental measurements, but following bakeout, the vacuum chamber typically reached pressures $\leqslant 10^{-10}$ torr. Composition of the base pressure gas and purity of intentionally 
introduced gases, i.e...Ar or $\mathrm{O}_{2}$, was monitored using a quadrupole residual gas analyzer. Laser transform modeling was accomplished by using the previously described apparatus. 15

C. Results

Following vacuum chamber bakeout, AES measurements on the $\mathrm{UO}_{2}$ surfaces indicated a significant amount of carbon surface contamination. Some chlorine, calcium, and sulfur impurity was also evident at this stage of the experiment. For these surface conditions the LEED patterns were barely visible over a bright background produced by diffuse electron scattering. Argon ion bombardment at energies $\leq 200 \mathrm{eV}$ was used to eliminate surface impurities. (Unlike the previous study, ${ }^{14}$ surface impurities could not be removed by just heating the samples to $<500^{\circ} \mathrm{C}$ in $\sim 10^{-6}$ torr $0_{2}$ ). The imbedded argon was largely desorbed from the samples after anneal to about $400^{\circ} \mathrm{C}$. For all the subsequent LEED results, AES showed no significant surface contamination.

1. The $\mathrm{UO}_{2}(100)$ Surface. The $\mathrm{UO}_{2}(100)$ surface did not facet at temperatures up to $950^{\circ} \mathrm{C}$. A well-ordered, clean $\mathrm{UO}_{2}(100)$ surface gave the spot pattern of Fig. 7A. The pattern is a $c(2 \times 2)$ where the $( \pm n / 2 \pm n / 2)$ spots. $n$ odd, are on the average much weaker than the other half order fcatures. The $( \pm 1 / 2 \pm 1 / 2)$ spots were visible only at incident energies below about $50 \mathrm{eV}$. All the half order spots could be eliminated frow the pattern by ion bombardment. The $c(2 \times 2)$ surface condition was difficult to analyze because the half-order spots were affectad by the incident electron beam. For incident energies near $100 \mathrm{eV}$, the $c(2 \times 2)$ pattern degraded in intensity unti?, after a period of hours beam time in the absence of gas phase $\mathrm{O}_{2}$, a variety of new nonintegral order features were observed. A sharp $c(4 \times 4)$ pattern, shown in Fig. $7 B$, was first formed under the electron beam. This was followed by the addition of more extra spots and the gradual formation of streaky crosses as shown in Fig. $7 \mathrm{C}$. Such pattern changes occurred much more rapidly during AES measurements, where larger incident current and energy ( $1 \mathrm{keV}$ ) were employed than in the LEED analysis. AES indicated no significant composittonal effects during the course of the beam induced surface changes. The $c(2 \times 2)$ spot pattern could be regenerated by heating the sample for a sufficiently long time at $\gtrsim 700^{\circ} \mathrm{C}$ and $\sim 10^{-9}$ torr pressure in the absence of the electron beam. These results agree with an earlier incomplete study of Uo 2 (100). 19

2. The $\mathrm{UO}_{2}(\sim 100)$ Vicinal Surfaces. As mentioned above, the four $\mathrm{UO}_{2}(\sim 100)$ vicinal surfaces examined in this work were distributed on two separate samples. 


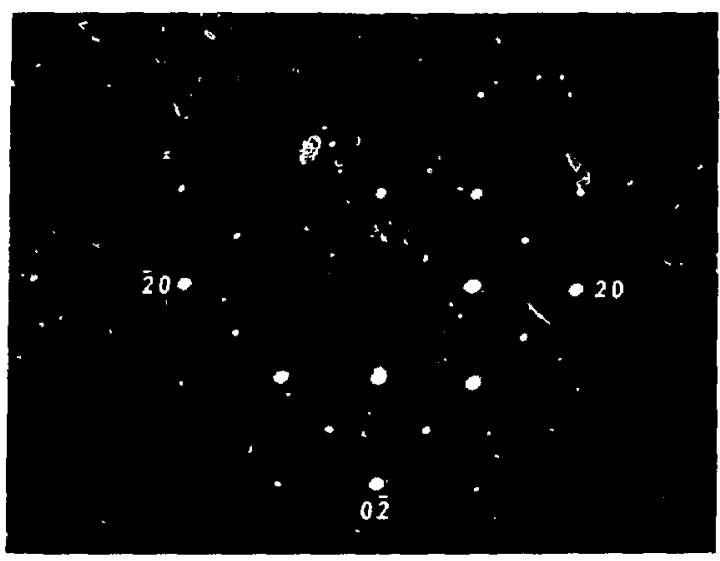

A

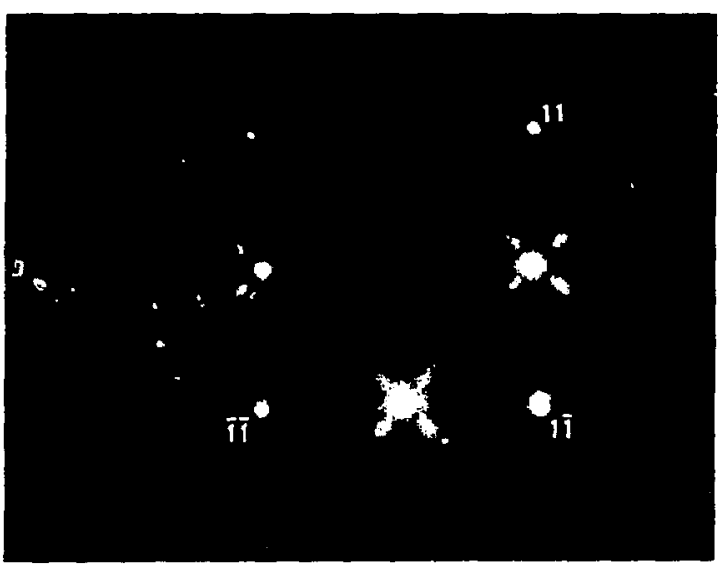

C

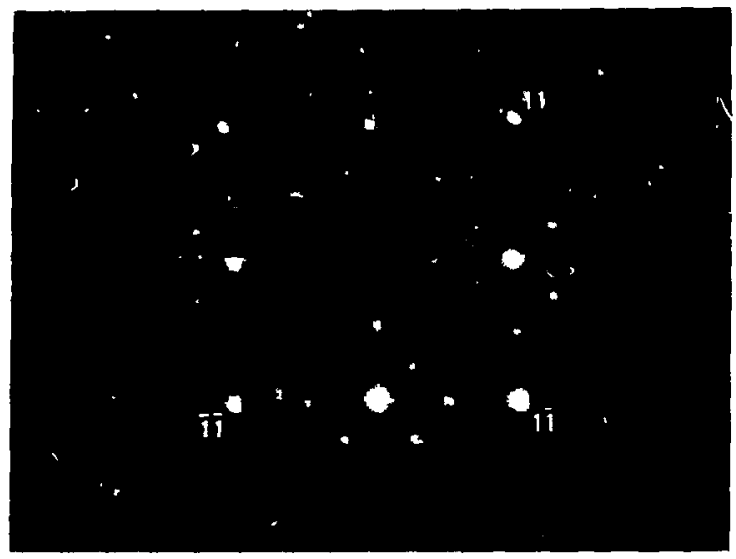

B

Fig. 7

A. $c(2 \times 2)$ spot pattern from the clean $\mathrm{vO}_{2}(100)$ surface at an incident energy of $124 \mathrm{eV}$.

B. Electron beam induced $c(4 \times 4)$ spot pattern from the $\mathrm{UO}_{2}(100)$ surface at an incident exergy of $57 \mathrm{eV}$. Missing spots visible at other energies.

C. Electron beam induced LEED pattern from the $\mathrm{UO}_{2}(100)$ surface at an incident energy of $57 \mathrm{eV}$. More beam exposure than photo $B$.

Each sample was analyzed in a separate set of measurements and in both cases care was taken to observe the ordering-faceting properties after increasing the temperature in increments of $50^{\circ}-100^{\circ} \mathrm{C}$.

a. Sample One: TL (711) and TLK surface E. After sample one was heated at $<500^{\circ} \mathrm{C}$ in $10^{-6}$ torr of $\mathrm{O}_{2}$, the clean (711) surface produced the spot pattern of Fig. 8A. Note that the doublet energy condition for an ordered (711) face is evident for diffraction near several of the (100) integral spot positions. The photograph of Fig. 8B shows the (711) diffraction pattern during the course of linearly varying the incident electron energy. The streaks produced by the motion of the diffraction spots converge to the specular reflection point for the surface. The angle between this convergence point and the drift tube, $\theta_{s}$, as 


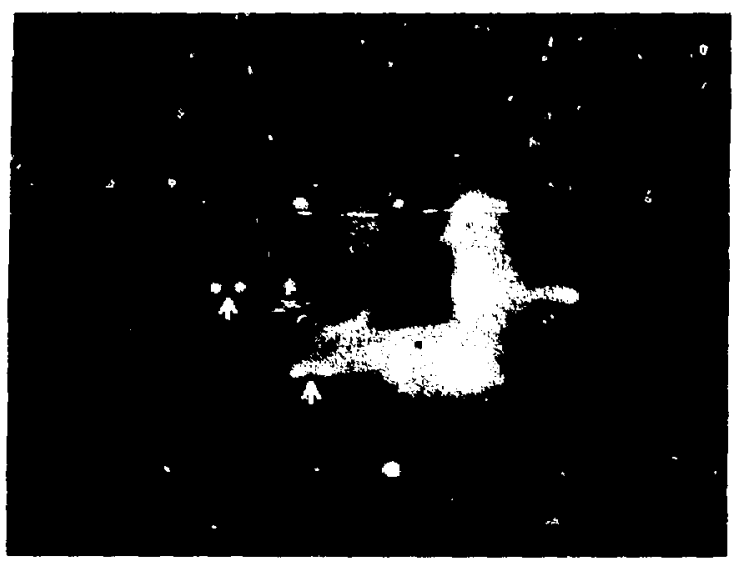

A

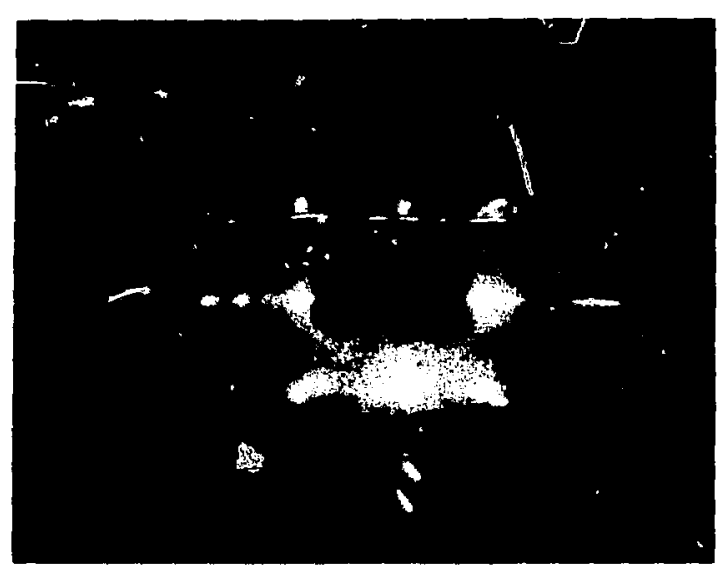

B

Fig. 8

A. Spot pattern from the ordered $\mathrm{UO}_{2}(711)$ surface at an incident energy of $124 \mathrm{eV}$. Arrows indicate doublet energy condition near (20) and (11) terrace spots.

B. Convergence photo obtained from the ordered $\mathrm{UO}_{2}(711)$ surface as the incident energy was swept from 100 to $160 \mathrm{eV}$. Incident electron beam normal to (100) face. " $x$ " indicates point of convergence on fluorescent screen.

measured from the sample position, is twice the polar angle, $\beta$, listed in the table of Fig. 5. Prior to measuring these angles the (100) surface was aligned normal to the incident electron beam. The sample was then translated normal to the incident beam until the desired vicinal surface was located. The angular positions on the fluorescent screen were calibrated from the position of the $(00)$ spot for known rotations of the (100) surface relative to the incident electron beam. As shown in Fig. 9A, heating the (711) surface above $600^{\circ} \mathrm{C}$ in $10^{-6}$ torr $\mathrm{O}_{2}$ produced diffraction features from two types of facets. For this surface condition the spot convergence photo of $\mathrm{Fig}$. 9B gives values of $\beta$ indicating the presence of (311) and (100) faceting. This facet array, indicated by the solid arrows pointing to [100] and $\langle 311\rangle$ from $\langle 711\rangle$ in Fig. 5, was the most ordered surface rearrangement observed during the course of the experiments on the (100) vicinal surfaces.

After heating the sample at $<500^{\circ} \mathrm{C}$ in $10^{-6}$ torr $\mathrm{O}_{2}$, LEED measurements on TLK surface $E$ showed an incomplete ordering of the closely spaced doublets shown in the photo of Fig. 10A. A convergence photo from this surface indicated a specular reflection consistent with the originaily prepared surface. Further heating to $<600^{\circ} \mathrm{C}$ introduced (100) facet features which could be identified 


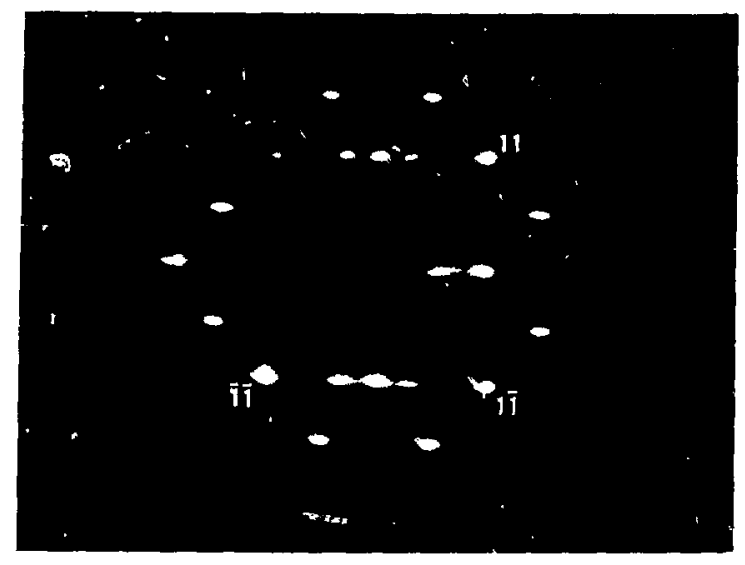

A

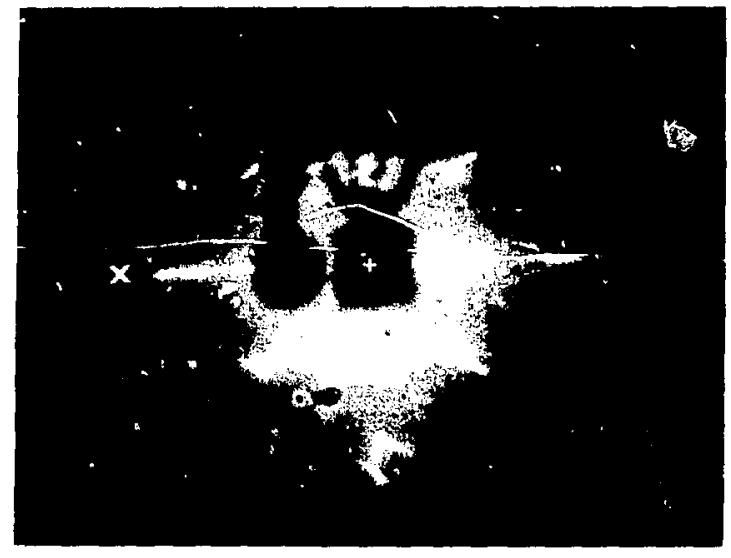

B

Fig. $\mathrm{S}$

A. Spot pattern obtained from the (711) prepared surface at the final facet stage. Incident energy is $91 \mathrm{eV}$. Nonindexed prominent sputs adjacent to (0I) spot are from (311) faceting.

B. Convergence photo obtained from fully faceted (711) prepared surface as the incident energy was swept from 92 to $146 \mathrm{eV}$. Incident electron beam norma 1 to (100) iace. " $x$ " indicates point of convergence from (311) facets on fluorescent screen. " + " indicates point of convergence (drift tube) from (100) facets.

either by translating the sample under the incident electron beam from surface $E$ to the (100) or by taking a convergence photo. Heating the sample above $600^{\circ} \mathrm{C}$ produced aduitional, poorly defined diffraction features indicating the presence of two sets of (311) facets. As shown by comparing Fig. 9A with Fig. 10B, the spacing and energy dependence of the latter diffraction streaks closely paralleled those seen from the ordered (311) facets of the (711) prepared face. The (311) faceting which gave the most intense diffraction features from surface $E$ is indicated by the solid arrow jointing to <311> from $E$ in $5 i g$. 5. The dasiled arrow from $E$ in Fig. 5 indicates the (311) facets associated with the less intense diffraction features. Thc LEED patterns from surface E were generally quite streaky. Both TL (711) and TLK surface E showed no further obvious changes when heated to $\sim 750^{\circ} \mathrm{C}$.

b. Sample Two: TL (711), TL (510), and TLK surface F. Following argon ion bombardment and anneal at $\lesssim 400^{\circ} \mathrm{C}$ for several hours in $\sim 10^{-6}$ torr $\mathrm{O}_{2}$, the various faces of sample two profuced vague doublets having the orientation and specular convergence properties of the prepared faces. The ordering was not as 


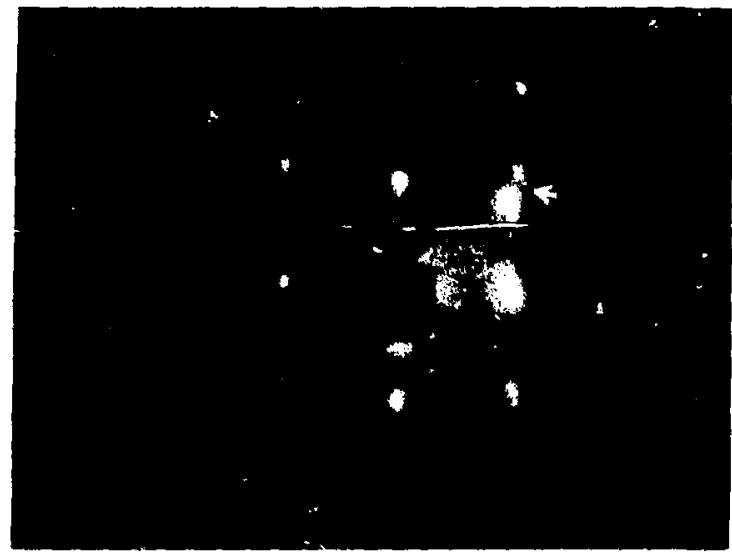

A

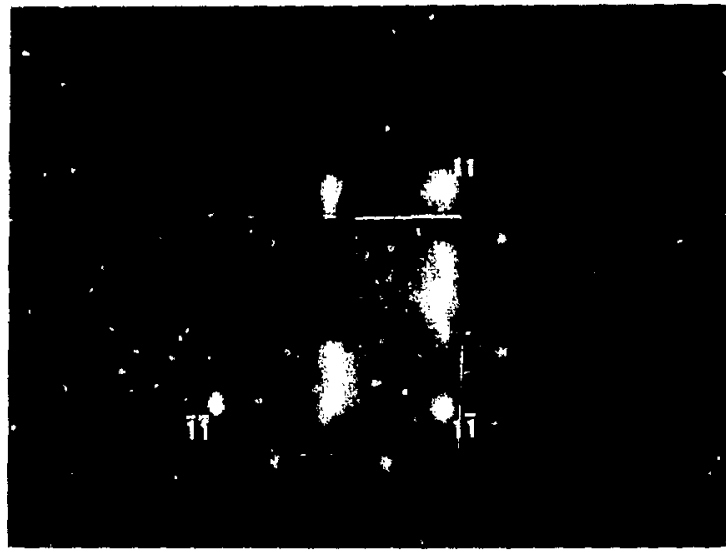

B

Fig. 10

A. Sharpest spot pattern obtained from TLK surface E prior to faceting. Incident energy is $75 \mathrm{eV}$. Arrow indicates doublet energy condition near (1I) spot location.

B. Spot pattern obtained from TLK surface E at the final facet stage. Incident energy is $90 \mathrm{eV}$. (100) facet spots are indexed. When compared to similar features in Fig. 9A, the streaky features adjacent the (10) spot indicate diffraction from a poorly ordered primary set of (311) facets oriented perpendicular to those of Fig. 9A. The secondary (311) features adjacent to the $(0 \overline{1})$ spot are too weak to be seen ill the photo.

well leveloped as that of the (711) surface of sample one. When sample two was heated for 24 hours in $\sim 10^{-9}$ torr vacuum at $\sim 450^{\circ} \mathrm{C}$, poorly ordered facet-1ike diffraction features were observed and further heating to $\sim 500^{\circ} \mathrm{C}$ gave LEED results indicating some (100) content on each of the three (100) vicinal surfaces. Heating to higher temperatures in $10^{-6}$ torr $O_{2}$ again produced the ordered (311) pli:s (100) facet configuration on the (711) prepared face. This faceting was stable in $\sim 10^{-8}$ torr vacuum for sample temperatures up to $950^{\circ} \mathrm{C}$ (higher temperature than was possible with sample one due to a different heater arrangement).

For the (510) surface and temperatures between 500 and $800^{\circ} \mathrm{C}$, fairly sharp diffraction features were observed in addition to those obviously associated with (100) faceting. Overlap of the former features with the (100) spots in a convergence photo obscured specular reflection. However, two sets of closely spaced but distinct non-(100) spots resulted from exposure of a photo at 90 and $117 \mathrm{eV}$. Extending a line through these doublet pairs indicated specular reflection very near that for the (410) plane. Heating above $800^{\circ} \mathrm{C}$ degraded these non-(100) diffraction features and produced streaks indicative of (311) faceting. 
The spacing and energy dependence of these diffraction streaks (shown in Fig. 11A) closely resembled that observed from the (311) faceting of the (711) prepared surface (see Fig. 9A). As indicated by the streak intensity in Fig. 11A, this latter faceting occurred in equal amounts in the two perpendicular directions

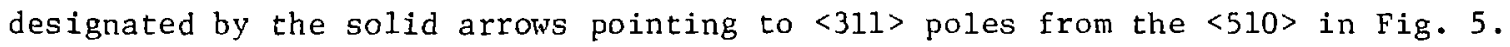

Between 600 and $800^{\circ} \mathrm{C}$, TLK surface F yielded diffraction that, with the exception of somc additional streaking, was similar to that seen on the (510) prepared face for this temperature range. As attested to by the LEED photos of Figs. $9 \mathrm{~A}$ and $11 \mathrm{~B}$, heating above $800^{\circ} \mathrm{C}$ again gave poorly defined diffraction features showing the presence of (311) faceting. However, unlike those seen from the (510) prepared surface, one set of diffraction streaks was more intense than the set seen at $90^{\circ}$. The solid arrow pointing to $\langle 311\rangle$ from $F$ in Fig. 5 indicates the (311) facets giving the more intense LEED features, while the dashed arrow from $F$ indicates the secondary set of (311) facets associated with the less intense diffraction.

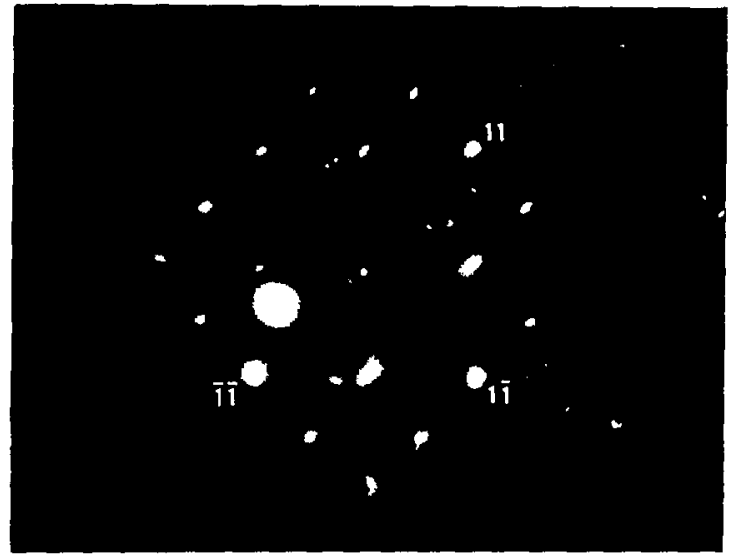

A

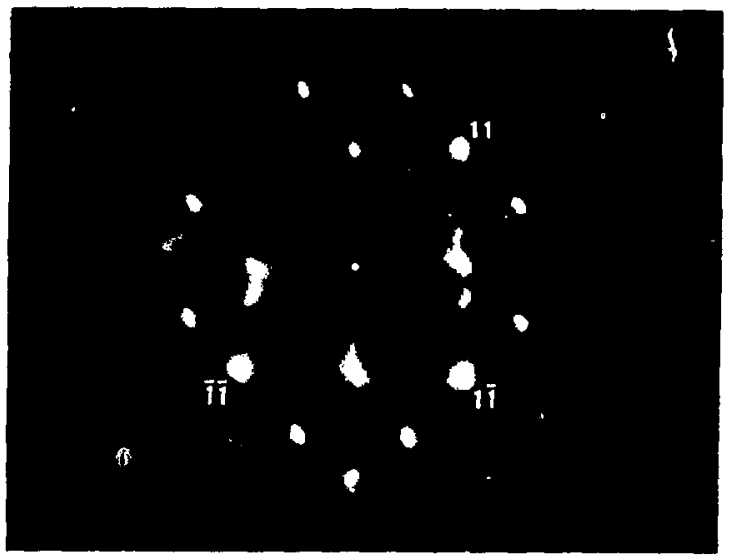

B

Fig. 11

A. Spot pattern obtained from (510) prepared surtace at the final facet siage. Incident energy is $91 \mathrm{eV}$. (1.00) facet spots are indexed. When compared to similar features in Fig. 9A, the streaky features adjacent to the (10) and $(0 \overline{1})$ spots indicate diffraction from two sets of poorly ordered (311) facets oriented perpendicular to one anothei.

B. Spot pattern obtained from TLK surface $F$ at the final facet stage. Incident energy is $91 \mathrm{eV}$. (100) facet spots are indexed. When compared to similar features in Fig. 9A, the streaky features adjacent to the (10) spot indicate diffraction from a poorly ordered primary set of (311) facets oriented perpendicular to those of Fig. 9A. Similar secondary (311) features are adjacent to the $(0 \bar{I})$ spot. 
AES spectra from the various surfaces of these two samples at each stage of the experiment did not differ significantly. The $c(2 \times 2)$ half order diffraction features from the nonfaceted vicinal cuts were elongated in a direction paral.lel to that defined by the observed doublets. (100) faceting inchanced the sharpness and intensity of these half order diffraction features.

3. The $\mathrm{UO}_{2}(\sim 111)$ Vicinal Surfaces. The $\mathrm{UO}_{2}(.111)$ vicinal surfaces were included in this study to determine the effect that ion bombardment would have on their ordering and faceting properties. Ion bombardment was not used as a cleaning technique in the previous measurements on these surfaces. ${ }^{14}$ The LFED results obtained on the $\mathrm{UO}_{2}(\sim 111)$ vicinal surfaces after argon ion bombardment as a function of temperature and oxygen treatment essentially agree with the past work. However, several minor variations in the diffraction features were observed which deserve mention.

As shown in Fig. 12A, a complete half order spot pattern was seen on the (111) surface. A half order pattern such as this was found after anneal near $700^{\circ} \mathrm{C}$ with or without $0_{2}$ in the gas phase. The pattern was degraded by the electron beam. Each of the three TLK surfaces exhibited half-urder features but at only one-third of the (111) half-order positions were they intense enough to be clearly resolvable as doublets. The remaining two-thlrds half-order

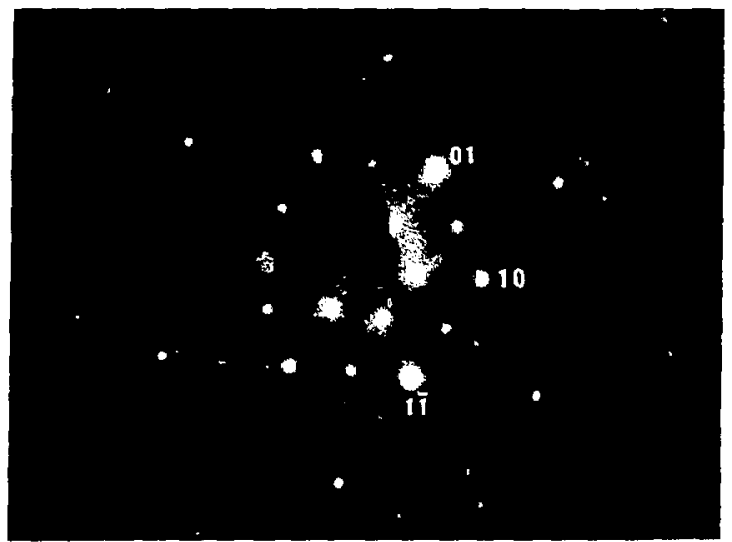

A

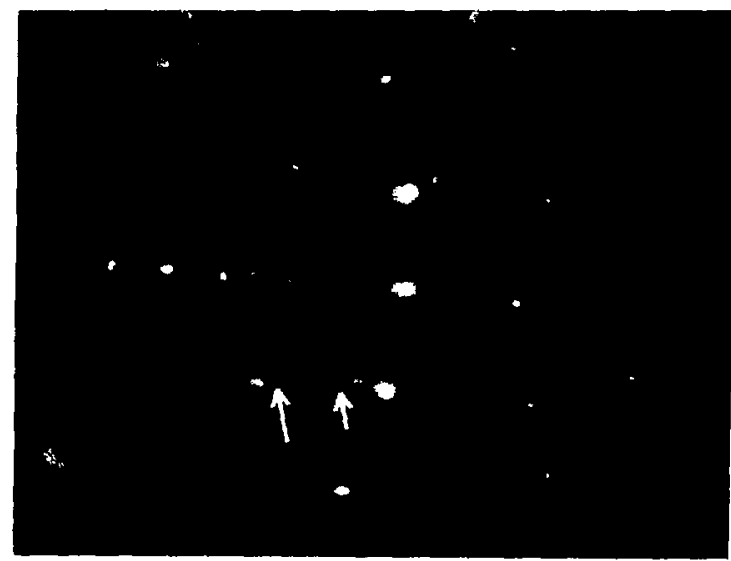

B

Fig. 12

A. Half-order spot pattern obtained from clean $\mathrm{UO}_{2}$ (111) surface. Incident energy is $88 \mathrm{eV}$.

B. Split half-order spot pattern obtained from clean $\mathrm{UO}_{2}(\sim 111)$ vicinal surface $\mathrm{D}$ (see Ref. 14). Incident energy is $102 \mathrm{eV}$. Short arrow points to (1/2 1 ) doublet. Long arrow points to (OI) doublet. 
positions were occupied by poorly delined, dim intensity reatures. One example of such a pattern is shown in Fig. 12B For TLK surface D.

After annealing TLK surface $A$ for one hour at $800^{\circ} \mathrm{C}$ in ultra high vacuum a triplet of split Bragg spots was photographed within the same angular spread as the doublets typically observed from this surface. Thesc diffraction fcatures are taken as evidence of an ordered array of double steps. At this stage in the measurements there was an obvious amount of (111) facet content on TIK surface D. The other two TLK surfaces may also have included some (111) faceting.

Neither the double stepping nor the (111) facet content was previously reported. $^{14}$ However, the split half-order spots were previously seen in much weaker form.

\section{Discussion}

As stated above, the vo $2(\sim 111)$ vicinal surfaces were included in this study to determine the effect that ion bombardment would have on their ordexing and faceting properties. The results indicate that bombardment introduces no dramatic changes in their previously reported ${ }^{14}$ behavior. The ion bombarded $\mathrm{UO}_{2}(\sim 111)$ vicinal surfaces exhibited ordering comparabje to that of the previous study. Thus, it is deemed more likely that ion bombardment, used as a necessary cleaning procedure on the $\mathrm{JO}_{2}(100)$ vicinal surfaces, was not the major cause for the disorder encountered with those surfaces. The (7j.1) prepared face, with its rearrangement into $(311)$ and (100) facets, was the only uo $2(100)$ vicinal surface to exhibit sharp, easily interpretable diffraction features.

The previous study of $\mathrm{UO}_{2}(\sim 111)$ vicinal surfaces ${ }^{14}$ reported intermediate faceting processes ( $i . e$. , rotating ledges) which could be reversed by heating in $\mathrm{O}_{2}$ at reduced temperatures to recreate the diffraction conditions of the original stepped surface. For those vicinal surfaces, the growth of (111) facets was not observed at temperatures up to $900^{\circ} \mathrm{C}$. In the present work, where the $10_{2}(\sim 111)$ vicinal sample was less perfectly prepared than in the earlier measurements, a minor amount of (111) facet growth was indicated by the LEED patterns. The rotating ledge properties were reproduced. The (100) vicinal surfaces showed a strong tendency to decompose directly to the nearby low index plane at temperatures much below $900^{\circ} \mathrm{C}$. No intermediate facet stages were observed which were reversible under heat treatment in $\mathrm{O}_{2}$. However, it is possible that such effects were overlooked because of the large amount of disorder exhibited by the LEED patterns. 
Well-defined ordering and final faceting on a stepped surface requires long range movement of a diffusing surface species. Such long range surface communication is evidently not the rule on the (100) vicinal surfaces where isolated microscopic surface rearrangement is prevalent. The fuurfuld (100) torraces, in contrast to the threefold (111) terraces, seem to act as surface diffusion barriers that limit long range surface communication while growing at the expense of intermediate faceting stages. The (311) facets have narrow terraces and thus permit better communication and more uniformity across the step arrangement. As was previously observed, ${ }^{14}$ the mobility and/or composition of the diffusing species on the (111) vicinal surfaces was definitely altered in the presence of $\mathrm{O}_{2}$ to enable reversal of the intermediate faceting sequence. Possibly a threefold uranium oxide molecule serves as the diffusing species which either is not readily produced or easily transported across the (100) terraces. Detailed ana1ysis of these effects would require more knowledge of the origin of the half order structures, mostly likely due to oxygen, seen on the two types of terraces.

The preservation of macroscopic surface orientation imposes qualitative restrictions on the facet composition of a surface. Figure 13A demonstrates that the appearance of (100) Eacets on the (711) surface requires steep interconnecting stepped surfaces. These interconnecting regions obviously need not exhibit the order or perfect (311) content of that shown in the drawing, Fig. $13 \mathrm{~B}$ represents a two-dimensional projection of a possible (100), TL, TLK facet

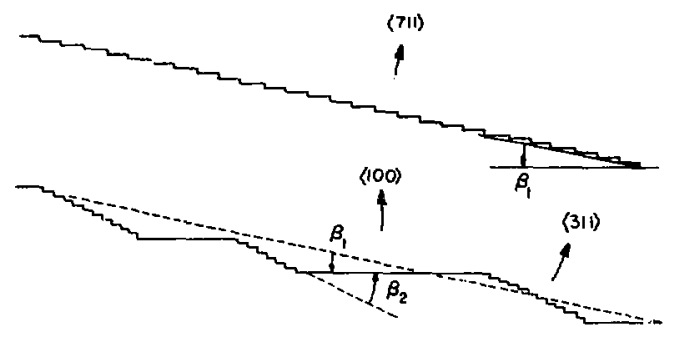

A
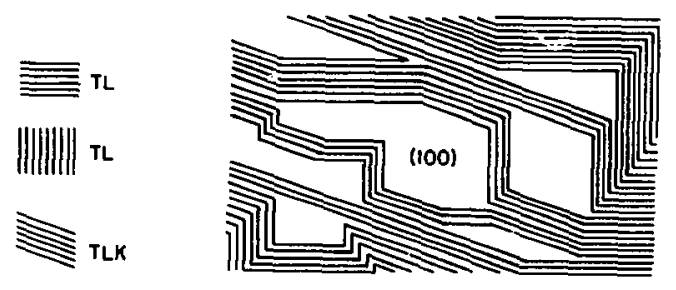

(110)

B

Fig. 13

A. Upper drawing: side view of (711) stepped surface, $\beta_{1}=11.4^{\circ}$. Lower drawing: side view of (100) and (311) facets obtained from the (71i) prepared surface, $B_{2}=25.2^{\circ}$.

B. Two-dimensional projection of a possible facet confjguration from TLK surface $E$. TL and TLK regions are not necessarily uniform. 
mixture which could yield the final diffraction results obtained from TLK surface E. In the model, the (1.00) "facets are joined by regions of TL (oriented in two perpendicular directions) and TLK to preserve the macroscopic surface oricntation. A number of pourly developed (311) regions must be present tn produco the streaky (311) diffraction features seen from surface E. An assortment of other TL and TLK regions are most likely present which also produce poorly defined diffraction features.

The previously reported half-order LEED pattern from the $\mathrm{UO}_{2}(111)$ surface was attributed to a $\mathrm{p}(2 \times 2)$ overlayer structure of oxygen. little attention was paid to split half tensity. However, in the present work these split half-urders were brighter and allowed a more detailed interpretation. The half-order spot pattern of Fig. 12A can result from a $p(2 \times 2)$ structure or a $(2 \times 1)$ structure of three equivalently oriented domains. The ambiruity between these two surface structures appears to be removed in the presence of a stepped surface. Overlooking the obvious intensity effects of doublet generation, Fig. 12B shows that the relative intensity of the half order doublets difiers considerably from the threefold intensity character expected from a $p(2 \times 2)$ structure. As seen in Fig. 12B twothirds of the half order doublets that would be anticipated with the $p(2 \times 2)$ structure are of extremely poor quality and very weak in intensity. A mismatch between the overlayer strictures on the various terraces would decrease the quality of all the half order doublets from a $p(2 \times 2)$ arrangement. Apparently the introduction of steps via a ( 111) TLK surface resulted in preferential selection of one of the three available $(2 \times 1)$ domains that precluded prominent ordered growth of the other two. The dominant split half-order spots of Fig. 12B can be explained by the (2xl) overlayer mesh on surface TLK D of Fig. 14. Each of the other two vicinal (111) TLK surfaces exhibited a set of intense split half-orders that correspond to (2x1) overlayer growth along equivalent crystallographic directions (also shown in Fig. 14). The vague half order features of Fig. 12B, could be derived from a minor amount of (111) faceting which, as seen in Fig. 12A, yields all three sets of $(2 \times 1)$ donains. Possibly random nonuniformities on the (111) face, in the form of simple steps or steps with kinks, serve as nucleation centers for approximately equal populations of the three ( $2 \times 1$ ) domains. The resultant half order pattern could not be distinguished from that of a $p(2 \times 2)$ overlayer structure without detailed intensity analysis. 


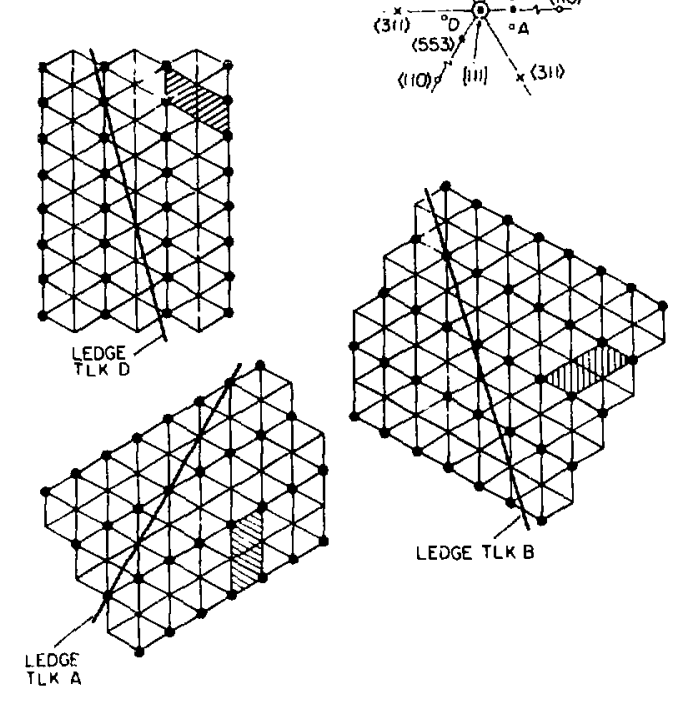

Fig. 14

Surface model showing orientation of dominant $(2 \times 1)$ unit mesh relative to the average ledge direction for the $\mathrm{UO}_{2}(\sim 111)$ vicinal suríaces of the inset see Ref. 14). Uranium atoms are located at triangle corners. Dots (') indicate (2xI) periodicity.

vicinal surfaces as compared to $\mathrm{UO}_{2}(\sim 111)$ vicinal surfaces reflects a difference in the oxygen bonding properties of the two fluorite materials. Thorium forms a narrowly stoichiometric oxide while uranium not only exhibits several valence states, but aiso forms hyper and hypostoichiometric $\mathrm{UO}_{2}$ via defect sites. The surface species responsible for the long-range communication between steps on such oxide surfaces is apparently more readily formed where metal atoms of multiple valence and oxygen defect structures are a possibility.

A summary of this work on $U_{2}(\sim 100)$ vicinal surfaces was presented by $W$. $P$. Ellis and T. N. Taylor at the International Conference on Colloids and Surfaces, ACS and the IUPAC, San Juan, Puerto Rico, 21-25 June 1976, under the title: "Configurations of Terrace - Ledge - Kink Arrays: LEED-Auger Studies of $\mathrm{UO}_{2}(\sim 100)$ Vicinal Surfaces." A manuscript relating in detail the $\mathrm{UO}_{2}(\sim 100)$ vicinal surface behavior has been prepared for submission to the journal "Surface Science." 


\section{MODIFICATIONS OF THE LEED-AUGER VACLUM CHAMRER FOR CATALYSIS STUDIES}

As mentioned in the introduction section, the NRIP project on catalysis $i_{i}$ CMB- 8 has been concerned only with catalytic reactions at $\leqslant 10^{-3}$ torr using a LEED-Aiger vacuum chaniber as the reaction vessel. The apparatus, as it was employed to study the $\mathrm{UO}_{2}(\sim 100)$ vicinal surfaces, requirea modifications fur catalysis measurements. A schematic of the LEED-Auger system as modified is drawn in Fig. 15. The reaction volume includes the LEED-Auger instrumentation, ionization gauge (IG), quadrupole residual gas analyzer (RGA), and ion bombardment gun. Reaction gases may be introduced into the reaction chamber through separate leak valves from high-pressure gas lines. A stainless steel capillary tube has been welded to the low-pressure port of one of the leak valves. With the tube directed at the sample (catalyst material), the effective pressure of the reaction gas at the sample surface is larger than the ambient pressure of the vacuum chamber. ${ }^{22}$ Thus, for experimental situations where a small amount of reaction gas is required to make an observation, the vacuum chamber need not be saturated with the gaswhich $i_{i}$ some instances involves a substaniial pump down time for attainment of ultra-high vacuum pressures. The sample can be positioned in front of the capillary tube and in line of sight of the RGA while still allowing LEED or AES

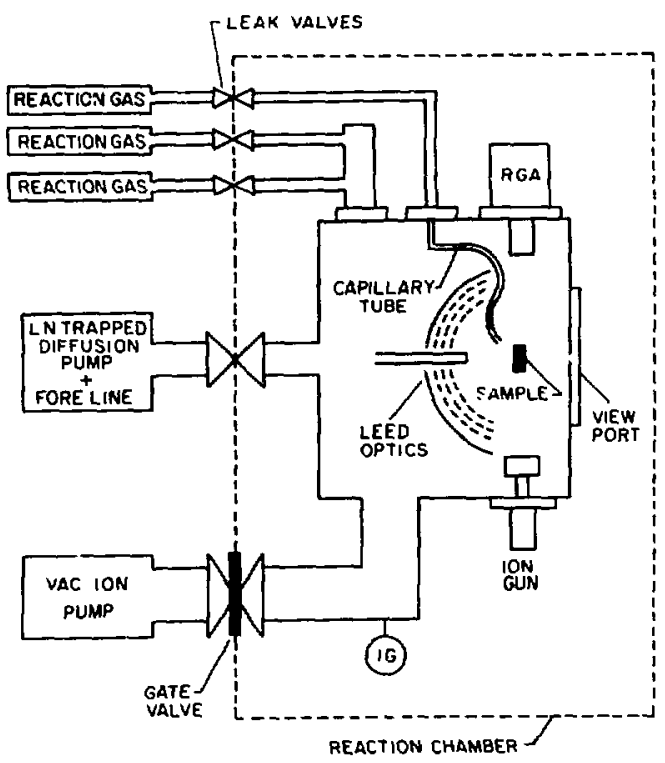

Fig. 15 measurements.

Prior to its conversion to a catalysis reaction vessel, the LEED-Auger system had only been utilized in ultrahigh vacuum applications where easily pumped elementa! gases were introduced at low pressures. Substantial Vacior. pump contamination resulted only during pump-down and bakeout when atmospheric gases and cleaning vapors dominated the gas composition. Pumping relatively large amounts of organic gases would adversely affect the performance of the VacIor pump and result in a higher system base pressure.

Schematic representation of LEED-Auger vacuum system as modified for use in the catalysis studies. 611 Hansen Way, Palo Alto, CA 94303. 
To meet the dual requirements for catalytic reactions at up to $10^{-3}$ torr pius LEEDAugux surface characterization at ultra-ingh vacuum pressures, two important changes were made in the vacuum chamber, as shown in Fig. 15. First an al1-meta1 gate valve was placed between the existing VacIon pump and the experimental section of the ricuum chamber or reaction vessel. The gate valve is completely bakeable to $\sim 225^{\circ} \mathrm{C}$. Second, a liquid nitrogen trapped diffusion pump was attached to the reaction chamber. A 2-3/4-in. a11-metal valve is used to separate the reaction vessel from the clean side of the trap. Optimum vacuum integrity was obtained from the diffusion pump (2-in. throat diam, water-cooled) by welding a 4-1/2-in. o.d. ConFlat ${ }^{(*}$ Flange to the entrance port. By using Convalex $\mathbb{B} * *$ (polyphenyl ether) pump ojl and proper bakeout of the trap prior to liquid nitrogen filling, the volume above the trap and below the 2-3/4-in. valve can routinely be pumped to $<2 \times 10^{-9}$ torr. With the gate valve closed and the $2-3 / 4-i n$. valve fully open, the diffusion pump station will hold the reaction chamier pressure $\leqslant 10^{-8}$ torr provided the chamber has been adequately baked. By closing the gate valve and opening the 2-3/4-in. valve to the diffusion pump, catalysis measurements at up to $10^{-3}$ torr can be made without impairing the performance of the Vacior. pumping station. By throttling or totally closing these valves, the reaction of interest can be done in a static or nearly static gas environment to prevent reaction products from being pumped below the detection limits of the RGA. LEED or AES examinatior of the catalyst can be accomplished at pressures in the $10^{-7}$ torr range or less. (The indirectly heated electron-emitting cathode is adversely affected at higher pressures by most reactant gases.)

The method used to heat the catalyst introduces a number of complications. Localized ohmic heating of a thin sample, a technique of ten applied to metals, is not feasible for the class of materials studied in this work. The presence of hot filaments, necessary for indirect heating or electron bombardment, must be eliminated from the reaction chamber to prevent introduction of spurious cracking and catalytic reactions. (Low-temperature filaments of thoriated iridium have been inserted into the ionization gauge and RGA.) In addition, the sample holder must be catalytically inactive while a portion of it is at the elevated temperatures required for catalysis on the attzched solid compound. A unique sample holder assembly was designed and built specifically to overcome these problems. As pictured in Fig. 16, the assembly consists of a hollow tantalum tip and hollow stainless steel body joined by electron beam welds to a stainless steel-tantalum

EVarian Associates, Vacuum Division, 611 Hansen Way, Palo Alto, CA 94303. * :CVC Products, Inc., P. O. Box 1886-7', Rochester, NY 14603. 


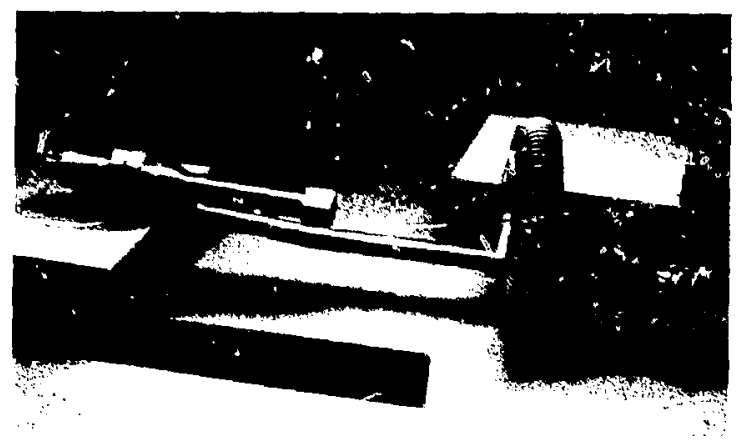

Fig. 16

Photo of sample holder assembly. Square tantalum tip face for mounting samples is located near the middle of the assembly. When placed in the modified LEED-Auger system, the assembly is suspended vertically from the reaction chamber manipulator. explosively bondud ring. The sample under investigation is pressed onto the tip zy a spot-welded tantalum clasp. The suprorting hody includes a Mini Conflat ${ }^{\mathbb{R}}$ connection and a stainless steel tube extending behind and beyond the tip. The Mini Conflat ${ }^{B}$ Plange is centered on the tip axis at the top of the assembly and mates to an electrical feed-through used to supply power to a triad of cathode heaters suspended inside the tip. The extended length of tubing behind the tip is welded to a bellows which coils once around the tip axis before being terminated by a second Mini Conflat connector. The

whole sample holder assimbly is suspended from the reaction chamber manipulator by a split-ring adapter fastened around the top Mini Conflat ${ }^{\circledR}$. When inserted in the reaction chimber, the cubing-bellows combination is coupled through a tubular ceramic isolator to an open-ended 2-3/4-in. Flange fitting attaclied to a bottom port of the reaction chamber. Thus, the internal volume of the sample holder can be pumped independently of the reaction chamber via plumbing connections to the diffusion pump and/or an 8 liter per sec Vacloi pump. The position of the tip, with sample attached, can be adjusted with the manipulator until the sample is located at the center of the LEED optics. The bellows is flexible enough to allow $\sim 180^{\circ}$ rotation about the sample manipulator axis. The whole assembly can be electrically isolated from ground so that the sample can be placed at a negative potential during ion bombardment. Sample temperatures are measured via a $W-26 \%$ Re-W thermocouple spot welded to the tip face opposite the sample.

Initial heating of the tantalum in the LEED-Auger or reaction chamber produced hydrogen outgassing sufficient to shut off the Vactor pumps (pressures in excess of $10^{-3}$ torr). By slowly increasing the temperature of the tantalum and using just the diffusion pump, the outgassing rate was eventually decreased to an acceptable level. With VacIor ${ }^{\mathbb{B}}$ pumping, the tip was outgassed for about 80 hours at $750^{\circ} \mathrm{C}$. At this stage the gases produced inside the sample holder assembly were easily handled by the 8 liter per second raclor. pump. With the 
tantalum tip heated to $600^{\circ} \mathrm{C}$ and the gate valve closed, the diffusion pumped base pressure of the reaction chamber was $2 \times 10^{-8}$ torr. For these same conditions and the gate valve open to the large VacIor. ${ }^{\circledR}$ pump, the base pressure of the reaction chamber was about $2 \times 10^{-9}$ torr. Following degassing, RGA ana?.ysis of the gas phase showed an increase in hydrogen, carbon monoxide, and carbon dioxide with increase in tip temperature. The maximum possible tip temperature for the power source available is $820^{\circ} \mathrm{C}$ at 33 watts input (11.25 Vrms, 2.95 Arms).

Tantalum was selected as a tip material because it was thought likely to be more catalytically inert than other readily available and machinable metals. During study of $\mathrm{CoO}$, a large propene product was thermally desorbed after exposure of the tip plus sample to isopropol alcohol. No LEED changes were noted from the $\mathrm{COO}$ after exposure to the alcohol and prior to heating. Apparently the tantalum tip, with a superficial oxide layer detectable by AES, dehydrated the alcohol. Such sample holder interference with catalys is product measurements can possibly be eliminated by properly coating the tjp with gold.

IV. STUDY OF COO, $\mathrm{Cr}_{2} \mathrm{O}_{3}$, AND UO 2 IN THE MODIFIED LEED-AUGER SYSiEM

As a first step towards understanding the catalysis of oxides, the surfaces of the materials involved in this study were characterized using the LEED-Auger instrumentation. This involved measurements on the surfaces following various sample treatments related to cleaning the surfaces or examining their reactivity to well-controlled gas environments below $10^{-3}$ torr. The latter interactions or chemisorption properties are quite vital in any analysis of catalytic phenomena. For a catalyst to evidence appreciable activity at least one component of the reaction gases should be chemisorbed ${ }^{23}$ on the catalyst surface (binding energy $\geq l e v)$. Gas species that are bound less strongly will be present on the surface in negligible numbers due to rapid desorption and may not be detectable with LEED-Auger.

$\mathrm{UO}_{2}$ being the exception, both $\mathrm{CoO}$ and $\mathrm{Cr}_{2} \mathrm{O}_{3}$ have been examined to a limited extent with modern surface analytical probes. In neither instance are there any reports of LEED done on single crystal samples of the macerials. For the latter two oxide materials, the clean surface properties measured via the LEED-Auger instrumentation are a definite object of interest prior to any study of chemisorption, and thus, catalysis effects. 


\section{A. Examination of $\mathrm{CoO}$}

Taken as a whole, cobult oxide materials - mixed and unmixed with other transition metal oxides and on various supports - display a great variety of catalytic chemistry. A siguificant amount of interest has been taken in the ability some of them have for removing organically bound sulfur from petroleum fractions (hydrodesulfurization most prominently using cobalt-molybdena-alumina) and for the purification of exhaust gases through oxidation/reduction of No, $\mathrm{CO}$, and other combustion related products. Previous phenomenological, i.e. kinetic, studies have been made on various catalyst materials containing CoO in order to analyze hydrogenation, dehydrogenation, and isomerization of hydrocarbons, ard oxidation reactions involving, for instance, armonia or alcohols. The following relates efforts made to characterize the chemisorption of various simple catalytically related gases when exposed to a CoO sample having pronounced single crystal structure.

Electron binding energies for $\mathrm{CoO}$ in polycrystalline form have been recorded in a number of $x$-ray photoelectron spectroscopy (XPS) studies. 24, 25, 26 The valence band spectra was shown 25 to be composed of peaks derived from cobalt $3 \mathrm{~d}$ levels, the oxygen $2 p$ level, and multielectron excitation. in that order proceeding from the fermi level to $\sim 10 \mathrm{eV}$ binding energy. In a study of thin $\mathrm{CoO}$ samples, Bakulin ${ }^{27}$ et al. reported transmission electron energy losses of 7.2 and $21.3 \mathrm{eV}$. As previously noted, no LEED-Auger measurements are available in the literature. This is undoubtedly in part due to the insulating properties of $\mathrm{CoO}$ which can cause pronounced charging effects in the presence of an electron beam.

CoO exhibits the NaCl crystal structure formed by a f.c.c. space lattice and a Co-0 atom basis where the metal atom and oxygen atom are separated by half the diagonal distance of the unit cube $\left(a_{0}=4.27 \AA\right)$. The (111) face is polar, i.e. the topmost layer of atoms is either co or 0 . while the (100) face is nonpolar, i.e. the topmost layer of atoms is equally populated with Co and 0 . The CoO sample analyzed in this study was an elliptically shaped wafer about $1 \mathrm{~cm}^{2}$ on a side. The outer periphery of the sample was oriented to expose the (111) face while the center portion contained a number of randomly oriented crystallites. One edge of the sample was cleaved to expose the (100) face. The cleaved surface was approximately 10 percent as large as the (111) face. After cutting and orier.ting to within $\pm 1 / 2^{\circ}$, the (111) face was polished with successively finer grit until a $1-\mu$ diamond paste was reached. Immediately prior to placement 
in the LFED-Auger chamber, the samplt was immersed in a 1:10 solution of phosphoric acid at room temperature for 65 sezonds and rinsed sequentially in deionized water and ethanol. The sample was mcunted on the tantalum holiter assembly.

AES examination of the CoO sample following bakeout with the base pressure $\leq 5 \times 10^{-10}$ torr indicated, in addition to the bulk constituents, $C$ and $C 1$ surface impurities. No electron diffraccion features were detectable over a bright background and, due to sample charging, LEED measurements were not possible below $\sim 50 \mathrm{eV}$.

Because in the early stages of the experiment the wire lead to the tantalum tip unknowingly became disconnected from the heater core, where the feedthrough wires were attached, the actual sample potential was poorly defined. The heater core was still in marginal contact with the tantalum tip. With this state of affairs the sample was argon ion bombarded - the gas continuously flowing through a leak valve and into the dirfusion pump. The applied acceleration potential was 200 volts. Following this treatment and prior to anneal, vague diffraction features were visible from the (111) and (100) surfaces. AES indicated significant $\mathrm{S}$ and $\mathrm{C}$ impurities. Heating to $500^{\circ} \mathrm{C}$ considerably reduced these two contaminants and introduced a noticeable $\mathrm{Ca}$ peak in the AES spectrum. Further heating up to $775^{\circ} \mathrm{C}$ also produced $\mathrm{K}$ segregation on the surface. Following anneal above $700^{\circ} \mathrm{C}$, the (111) surface produced a diffuse thren-fold diffraction pattern with a slight suggestion of half-order features. The (100) surface gave much sharper diffraction and, as shown on Fig. 17 for this stage of the experimentation, streaking and (2x1) half-order spots were often seen between the integral-order features. The composition of the (100) face was difficult to measure reliably with AES due to the narrowness and charging of the face. Large :andomly oriented four-fold facets were detected in the multi-crystalline center portion of the sample. The LEED pattern from such a surface is shown in Fig. 18. The surface content of the center portion of the sample, measured via AES, did not differ significantly from that of the (111) periphery. Sample charging interfered with LEED measurements for incident energies $\leqslant 80 \mathrm{eV}$. Heating the sample at $820^{\circ} \mathrm{C}$ one hour in $\sim 10^{-6}$ torr oxygen produced no obvious LEED or AES changes.

After the disconnected wire lead had been found, the sample was properly ion bombarded at $250 \mathrm{eV}\left(4 \times 10^{-4}\right.$ torr, $25^{\circ} \mathrm{C}, 1.25 \mathrm{hr}$.) by applying the acceleration potential directly to the tantalum tip via the spot welded thermocouple. (During the course of subsequent measurements the sample was also properly grounded through the thermocouple.) Following anneal in vacuo for about 4 hours at $820^{\circ} \mathrm{C}$, 


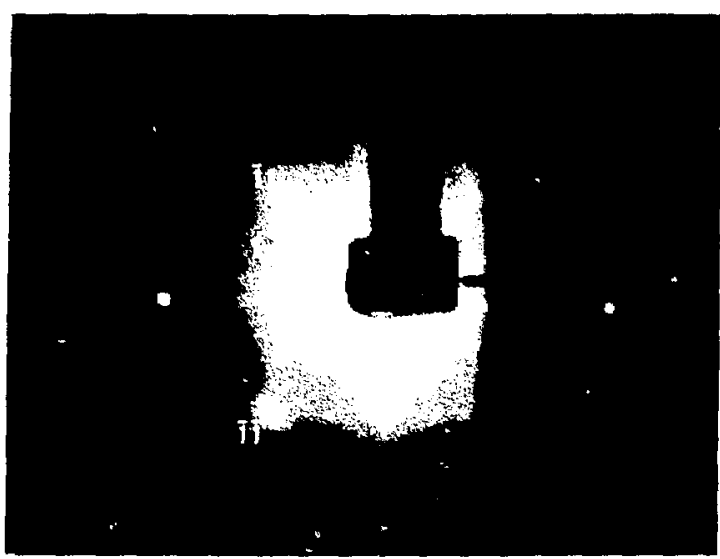

Fig. 17

Spot pattern obtained from CoO(100) surface at a metered incident energy of $145 \mathrm{eV}$. Sample had been argon ton bombarded and heated as high as $775^{\circ} \mathrm{C}$ in vacuo. AES done on the major sample face indicated some $\mathrm{S}, \mathrm{K}, \mathrm{C}$, and $\mathrm{Ca}$ surface impurities.

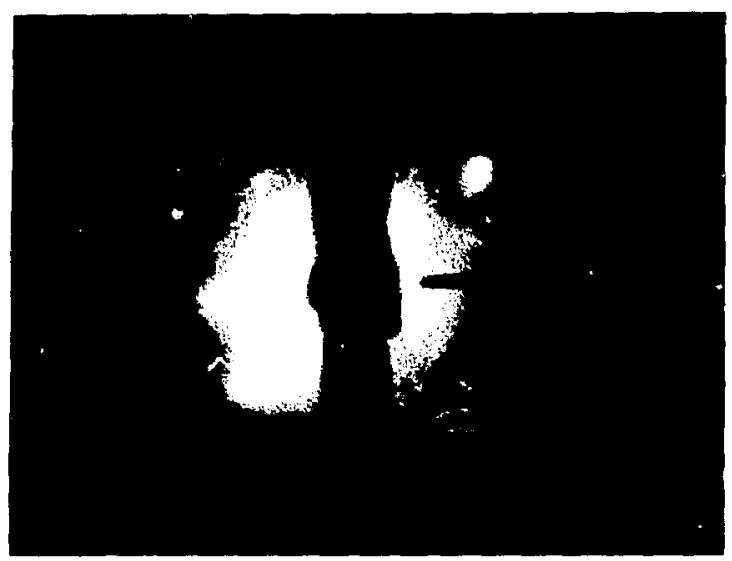

Fig. 18

Spot pattern obtained from a fourfold facet located in the multi-crystalline center portion of the CoO sample. Metered incident energy is $175 \mathrm{eV}$. Following treatment of Fig. 17, sample was heated at $820^{\circ} \mathrm{C}$ in vacuo and at $700^{\circ} \mathrm{C}$ in $10^{-6}$ torr of oxygen.

the half order LFED pattern of Fig. 19A was produced by the (111) surface. AES indicated significant $\mathrm{K}$ and $\mathrm{Ca}$ surface contamination. There was a small $\mathrm{S} i \mathrm{~m}-$. purity and no residual $\mathrm{Cl}$ or $\mathrm{C}$. All these impurities were reduced to the noise level of the Auger spectrometer by heating the sample at $600^{\circ}-700^{\circ} \mathrm{C}$ and simultaneously ion bombarding at $200 \mathrm{eV}$ over a time period of hours. After heating the sample to $820^{\circ} \mathrm{C}$ in vacuo, the photograph of Fig. 19B was taken where AES at $1.5 \mathrm{KeV}$ incident energy showed only Co and 0 . Immediately after cooling to near $25^{\circ} \mathrm{C}$, LEED measurements were possible for several minutes at incident energies as $10 \mathrm{w}$ as $30 \mathrm{eV}$. However, continuous exposure to the electron beam eventually charged the sample and extinguished the LEED pattern for incideni energies $\leqslant 100$ $\mathrm{eV}$. During the course of the remaining measurements on CoO, LEED pattern instabilities and AES noise associated with sample charging were greatly reduced by elevating the sample temperature to $100^{\circ}-200^{\circ} \mathrm{C}$. The LEED pattern from the (111) surface was still much more diffuse than that seen from the (100) face, where in the latter case streaking was visible between the integral order spots.

Electron energy loss measurements were also taken from the clean CoO surfaces. In making these inelastic measurements, the secondary electron energy spectrum, $N(E)$, is examined as a functinn of incident energy to locate peaks 

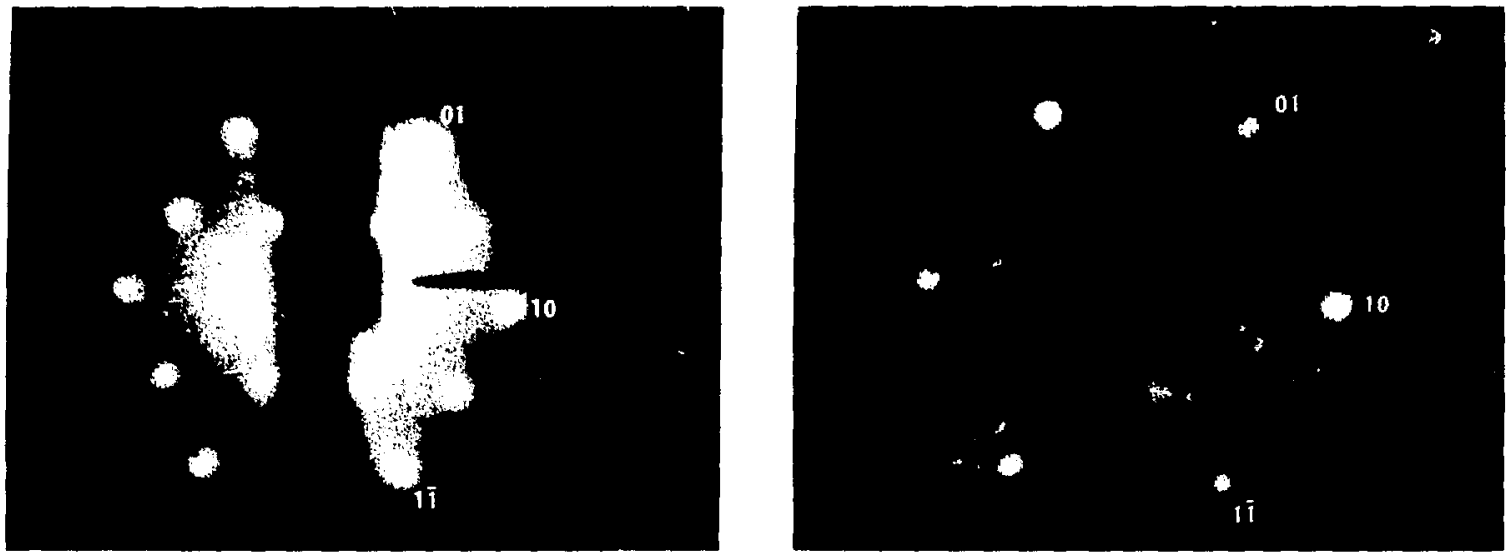

Fig. 19

A

Half order spot pattern obtained from Coo(111) surface at a metered incident energy of $67 \mathrm{eV}$. Sample treatment and surface condition is described in text.

Integral-order spot pattern obtained from clean CoO(111) at a metered incident energy of $59 \mathrm{eV}$.

that are a fixed energy below the elastic peak. The LEED optics is used in the AES mode to detect $N(E)$ versus $E$. Loss peaks can often times be associated with atomic levels, plasmon oscillations, or interband transitions. Trace A of Fig. 20 is the electron loss spectrum obtained from clean $\mathrm{COO}$ where loss peaks are found $8,15,34$, and $61 \mathrm{eV}$ below the elastic peak. The losses were recorded between 100 and $600 \mathrm{eV}$ incident energy and were invariant at the (100), (111), and center portions of the sample.

When the CoO sample was exposed to the gases listed in Table I, no adsorption effects were observed for the conditions stated. The LEED patterns were unchanged from that of the original surface condition. AES was employed in an attempt to detect $\mathrm{C}$ from hydrocarbon or alcohol adsorption and to detect $\mathrm{N}$ for nitric oxide or ammonia adsorption. The sample temperature varied according to the charging problems encountered. In all cases where more than $\sim 10^{-7}$ torr pressure is listed, the gate valve was closed and the diffusion pump used to establish a flow of gas through the reaction chamber.

Water, however, was observed to react with $\mathrm{CoO}$ - but only in the presence of the electron beam. Trace B of Fig. 20 shows the changes produced in the energy loss spectrum after exposure of $\mathrm{CoO}$ to water vapor in the mid $10^{-8}$ torr range. If the electron beam was moved to a different location on the sample, the 


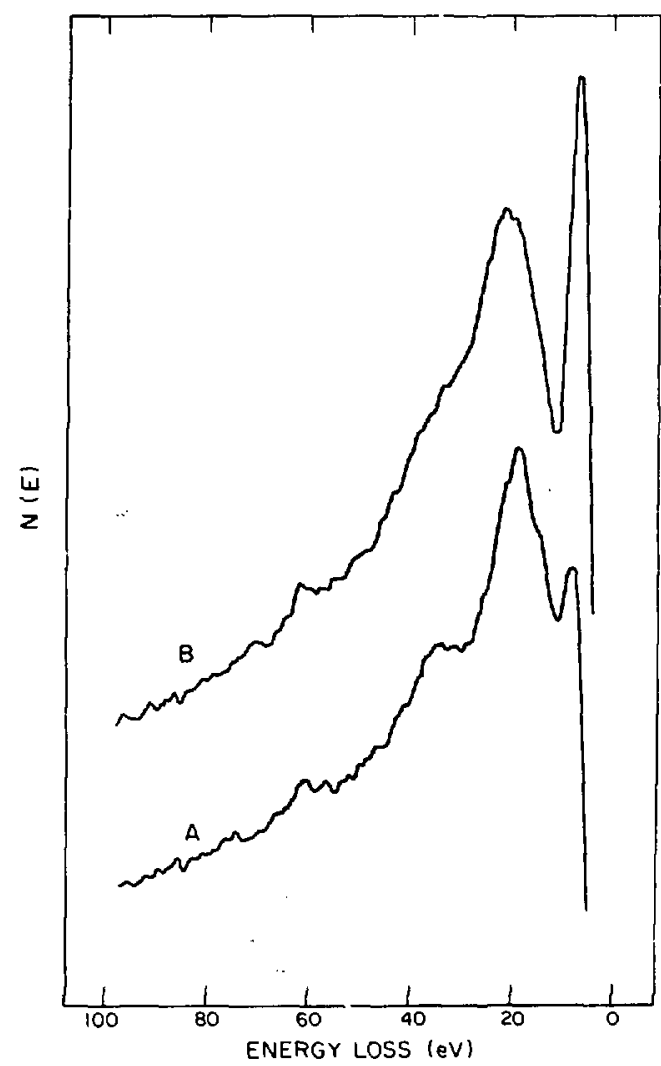

Fig. 20

Electron energy loss spectra from CoO at a metered incident energy of $198 \mathrm{eV}$. Trace A taken from clean CoO. Trace $B$ after exposure of $\mathrm{COO}$ to water vapor at $6 \times 10^{-8}$ torr in the presence of the electron beam. clean CoO energy loss spectrum was obtained. The growth of the $8 \mathrm{eV}$ loss peak with exposure to water was accompanied by a large increase in LEED background and subsequent loss of diffraction spots. After heating the sample to $800^{\circ} \mathrm{C}$ the energy loss spectrum returned to that seen prior to exposure to the water vapor. When water vapor and cyclopropane were inlet into the reaction chamber simultaneously at $<10^{-7}$ torr total pressure, the energy lcss spectrum of trace $B$ in Fig. 20 was again recorded. Subsequent AES un this electron beam affected area of the sample indicated the absence of surface carbon and hence, cyclopropane chemisorption.

B. Examination of $\mathrm{Cr}_{2} \mathrm{O}_{3}$

The catalytic properties of chromia, $\mathrm{Cr}_{2} \mathrm{O}_{3}$, have been a subject of interest for decades. This material has most notably been applied commercially to the dehydrogenation of olefins and to dehydrocyclization of heptane to toluene. Chromia in the form of a hy-

drated gel requires pretreatment of elevated temperature for development of its catalytic and adsorptive capacity. Burwe $11^{28}$ has proposed that the loss of water during such heating creates coordinatively unsaturated bonds that are the active sites on the catalyst surface. Annealing the hydrated material at a high enough temperature completely releases the bound water and produces crystalline $\alpha-\mathrm{Cr}_{2} \mathrm{O}_{3}$. Thus, the interaction of water vapor with $\mathrm{Cr}_{2} \mathrm{O}_{3}$ is of primary importance to the present study of the material's catalytic properties.

Alpha-chromia exhibits the corundum structure 29,30 which can be viawed as a slightly distorted hexagonal close-packing of oxygen atoms with metal 
TABLE I

FXPOSURE OF COO TO VARIOUS GASES

\begin{tabular}{|c|c|c|c|}
\hline Gas Phase & $\begin{array}{l}\text { Pressure } \\
(\text { torr }) \\
\end{array}$ & Surface & Comments \\
\hline \multirow[t]{2}{*}{ Cyclopropane } & $10^{-5}$ & Clean & $\begin{array}{l}\text { No adsorption, AES, LEED, minutes of } \\
\text { exposure, } \mathrm{T}=200^{\circ} \mathrm{C} \text {, with } \mathrm{H}_{2} \mathrm{O} \text { present }\end{array}$ \\
\hline & $1.0^{-7}$ & Clean & $\begin{array}{l}\text { No adsorption, electron loss, more than } 10 \\
\text { min exposure, } \mathrm{T}=200^{\circ} \mathrm{C} \text {, with } \mathrm{H}_{2} \mathrm{O} \text { present }\end{array}$ \\
\hline Propene & $2 \times 10^{-8}$ & $\begin{array}{l}\mathrm{K}, \mathrm{Ca} \\
\text { impurity }\end{array}$ & $\begin{array}{l}\text { No adsorption, LEED, AES, } 1 \mathrm{hr} \text {. exposure, } \\
\mathrm{T} \sim 25^{\circ} \mathrm{C}\end{array}$ \\
\hline \multirow[t]{3}{*}{ Methanol } & $10^{-6}$ & clean & $\begin{array}{l}\text { No adsorption, LEED, AES, minutes exposure, } \\
T=200^{\circ} \mathrm{C}\end{array}$ \\
\hline & $10^{-7}$ & Clcan & $\begin{array}{l}\text { No adsorption, el ctron loss, } 10 \text { minutes } \\
\text { exposure, } \mathrm{T} \sim 25^{\circ} \mathrm{C}\end{array}$ \\
\hline & $5 \times 10^{-6}$ & $\begin{array}{l}\mathrm{K}, \mathrm{Ca} \\
\text { impurity }\end{array}$ & $\begin{array}{l}\text { No adsorption, LEED, AES, } 1.5-2 \mathrm{hr} \text {. ex- } \\
\text { posure, } \mathrm{I} \sim 25^{\circ} \mathrm{C}\end{array}$ \\
\hline Isopropanol & $10^{-5}$ & Ciean & $\begin{array}{l}\text { No adsorption, LEED after pressure lower- } \\
\text { ed, } \mathrm{T}=175^{\circ} \mathrm{C} \text {, AES hours after exposure }\end{array}$ \\
\hline Toluene & $10^{-6}$ & Clean & $\begin{array}{l}\text { No adsorption, LEED, AES, over an hour ex- } \\
\text { posure before } 20 \mathrm{~min} \text { pump-down to } 10^{-8} \\
\text { torr range, } \mathrm{T} \sim 25^{\circ} \mathrm{C}\end{array}$ \\
\hline Nitric oxide & $5 \times 10^{-8}$ & Clean & $\begin{array}{l}\text { No adsorption, LEED, AES, electron loss, } \\
40 \text { min exposure for } \Lambda E S, T=125^{\circ} \mathrm{C}\end{array}$ \\
\hline Ammonia & $3 \times 10^{-8}$ & Clean & $\begin{array}{l}\text { No adsorption, LEED, AES, } 30 \mathrm{~min} \text { ex- } \\
\text { posure, } T=150^{\circ} \mathrm{C}\end{array}$ \\
\hline
\end{tabular}

atoms in two-thirds of the octahedrally coordinated holes between the oxygen atoms. When viewed down this stacking axis, i.e. normal to the (Uv01) plane, the topmost layers of $\mathrm{Cr}$ and $O$ appear as in Fig. 21. The unit cell vectors in this plane are as shown in Fig. 21, where $a_{0}=4.954 \AA$. Note that because only two-thirds of the octahedrally coordinated holes between oxygen atoms are filled with $\mathrm{Cr}$ atoms, the surface mesh is nonprimitive (two $\mathrm{Cr}$ atoms per mesh). When examined via LEFD, the (0001) net constructed from this nonprimitive mesh produces a hexagonal spot pattern.

The $\alpha-\mathrm{Cr}_{2} \mathrm{O}_{3}$ sample used in this study was a wafer of approximately $0.25 \mathrm{~cm}^{2}$ on each side. It had been cut from a $\mathrm{Cr}_{2} \mathrm{O}_{3}$ ingot and oriented to expose the (0001) face to within $\pm 1 / 2^{\circ}$ as verified via $x$-ray diffraction. The oriented 

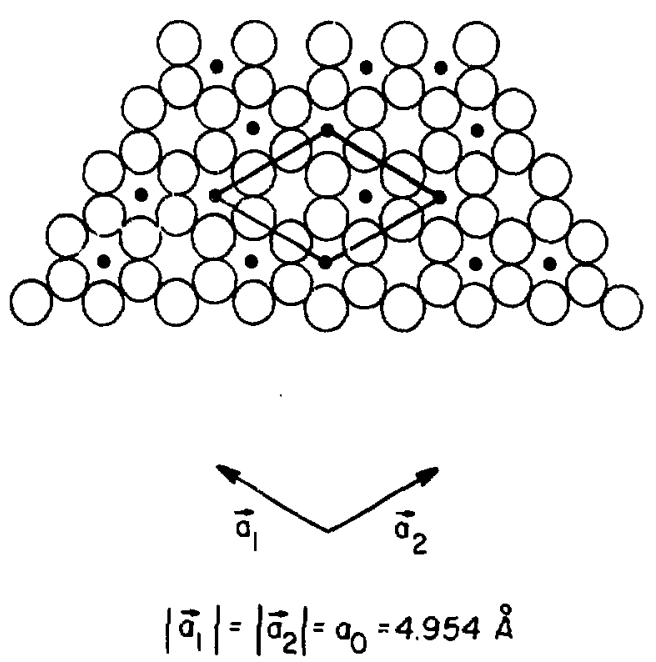

Fig. 21

vrawing depicting the $\mathrm{Cr}$ and $\mathrm{O}$ crystallography in the topmost layers of a $\mathrm{Cr}_{2} \mathrm{O}_{3}(0001)$ surface. Dots (') indicate $\mathrm{Cr}$ atoms. Large circles indicate $\mathrm{O}$ atoms. Nonprimitive unit mesh is shown where $\vec{a}_{1}$ and $\vec{a}_{2}$ are the unit mesh vectors.

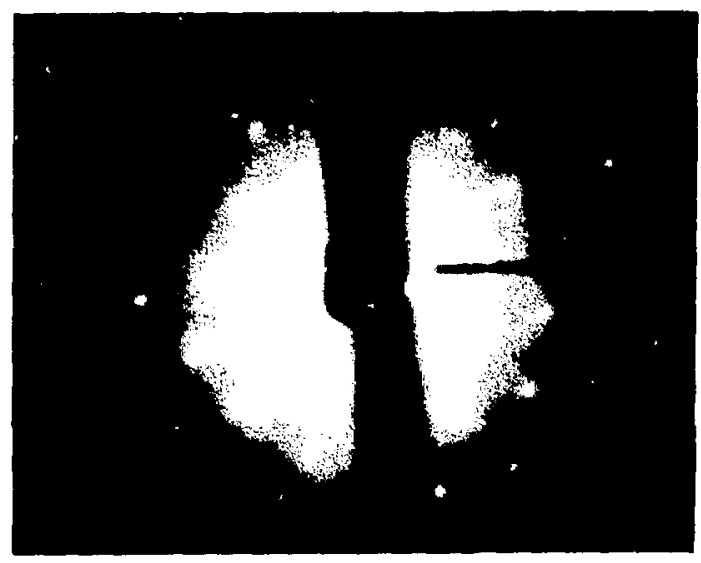

Fig. 22

Hexagonal spot pattern from $\mathrm{Cr}_{2} \mathrm{O}_{3}(0001)$ prior to bakeout and any surface treatment in vacuo. Metered incident energy is $156 \mathrm{EV}$. (00) spot near drift tube. face was polished with successively finer grit until a $1-\mu$ diamond paste was reached. Immediately prior to placement in the LEED-Auger chamber, the sample was imnersed in fused potassium bisulfate at $350^{\circ} \mathrm{C}$ for two minutes. After removal from the hot etchant and cooling to room temperature, the remnant salt was rinsed away with tap water followed by ultrasonic washing sequentially in deionized water, trichloroethylene, and acetone. The $\mathrm{Cr}_{2} \mathrm{O}_{3}$ sample was then mounted on the tantalum holder assembly.

\section{Immediately after introduction}

into the LEED-Auger chamber, i.e. before bakeout, a remarkably sharp LEED pattern was observed from the $\mathrm{Cr}_{2} \mathrm{O}_{3}$ (0001) surface as shown in Fig. 22. Individual diffraction spots were still clearly resolvable at metered incident energies as high as $800 \mathrm{eV}$. AES measurements showed that $\mathrm{K}$ was the only significant surface impurity. The ambient gas in the LEED-Auger chamber during these measurements consisted mostly of water vapor (total pressure $\sim 3 \times 10^{-7}$ torr). As was the case with CoO, LEED pattern instabilities and Auger spectrometer noise resulted from sample charging. No further measurements were possible on this $\mathrm{Cr}_{2} \mathrm{O}_{3}$ sample before filing the final NRIP report. The direction that such measurements should take are discussed in the concluding section of this report. 


\section{Examination of $\mathrm{UO}_{2}$}

Interest in the catalytic properties of uranium and 1ts compounds has existed since the early 1900s. The relatively recent avallability of depleted uranium has prompted continued catalytic investigation of these materials. Reviews 31,32 written covering the pre-1960 period of study indicate that uranium oxides have received the bulk of attention on uianium compounds. More recently uranium has been applied to treatmant of exhaust gases from internal combustion engines 33,34 and its oxides have been analyzed for dehydrogenation and dehydration of ethanol ${ }^{35}$ and as promoters for iron catalysts in ammonia synthesis. 36 Colmenares of Lawrence Livermore Laboratory has investigated the conversion of cyclohexane to benzene on uranium powders at elevated temperatures and atmospheric pressures. ${ }^{37}$ He has also compiled a bibliography of articles written on the catalysis of thorium and uranium. 38

The fully faceted $\mathrm{UO}_{2}(\sim 111)$ and $(\sim 100)$ "sample one" were examined for their interaction with cyclopropane and propene. This was done in the modified LEEDAuger system without use of the tantalum holder assembly. The samples were mounted next to each other on a stainless steel holder by means of a Pt mesh. No new LEED features were observed from the various faces after exposure to cyclopropane at $\leqslant 2 \times 10^{-8}$ torr for approximately one hour. LEED was also used to examine these surfaces after several minutes of exposure $:, 5 \times 10^{-6}$ torr propene prior to poisoning of the electron gun cathode. Again, no new diffraction effects were seen.

D. Discussion

The most notable result derived from Lhis low-pressure stıdy of $\mathrm{CoO}_{,} \mathrm{Cr}_{2} \mathrm{O}_{3}$, and $\mathrm{UO}_{2}$ is their failure to adsorb any measurable amount of base pressure or intentionally introduced reaction gas. CoO strongly interacted with water vapor - but only in the presence of an electron beam. $\mathrm{UO}_{2}$ did not chemisorb cyclopropane or propene, and $\mathrm{Cr}_{2} \mathrm{O}_{3}$ has no affinity for the hydrocarbons typically found in an unbaked vacuum system.

The limitations imposed on the measurements by sample charging (increased sample temperature) and gun cathode poisoning (pressures $\leqslant 10^{-7}$ torr) severely restrict study of such weakly interacting gas-solid combinations. Strong chemisorption should be detectable with these limitations present even if slow surface build-up results from a small sticking coefficient. Sufficient increase in exposure (pressure $x$ time) should yield a measurable surface concentration of 
adsorbed reactant gas that does not significantly decrease until well after the pressure is lowered to a value which allows use of the electron gun. For instance, with an exposure at $10^{-6}$ torr for 5 minutes (where approximately one monolayer of gas molecules is incident ori a surface per second) a sticking coeficient of $1 / 3000$ would still give a tenth of a monolayer. With reference to Table I, strong chemisorption certainly did not ocisur with toluene where not only the exposure time and pressure were large, but also the sample temperaturt " is not elevated.

Methanol has been observed to chemisorb on alumina ${ }^{39}$ and magnesia ${ }^{40}$ powder at $10^{-5}$ torr and room temperature. The adsorbed species did not appreciably desorb during a 30-minute pump-out time following the exposure. It would be of definite interest to examine the adsorption properties of large crystalline forms of these materials. Behavior like that of the COO sample examined in this study would indicate that "active sites," present only in appreciable numbers on powders, are responsible for the alcohol chemisorption.

Measurements have been made of No adsorption on polycrystalline $\mathrm{Co}_{3} \mathrm{O}_{4}$ using $x$-ray photoelectron spectroscopy. ${ }^{4]}$. The NO adsorption was accomplished at a sample temperature of $-100^{\circ} \mathrm{C}$ and an exposure of $2 \times 10^{-5}$ torr for 3 hours. The vacuum chamber was then evacuated to the $10^{-7}$ torr range before the sample was heated. A weak $\mathrm{N}$ signal was detectable at $150^{\circ} \mathrm{C}$. No measurements were made for exposures above $-100^{\circ} \mathrm{C}$. It is possible that room-temperature adsorption might be significantly smaller than that found at room temperature after exposing at $-100^{\circ} \mathrm{C}$. The high surface density of adsorbed molecules attained at $-100^{\circ} \mathrm{C}$ might produce a collective interaction that yields a surface species with stronger bonding properties than possible when molecules are individually adsorbed at room temperature. This line of reasoning suggests that readily detectable adsorbed species may be found on $\mathrm{CoO}, \mathrm{Cr}_{2} \mathrm{O}_{3}$, or $\mathrm{UO}_{2}$ at $\lesssim 10^{-7}$ torr through adsorption at low temperature followed by heating to the temperatures used in this study.

\section{FINAL SUMMARY}

The work presented in this report represents a significant step towards the completion of the first in situ study of heterogeneous catalysis on solid compounds in a LEED-Aurer system. Information on the ordering and faceting properties of a totally new set of $\mathrm{UO}_{2}$ surfaces, vicinal to the (100) face, has been added to the already extensive knowledge on $\mathrm{vO}_{2}$ in Group CMB-8. The LEED-Auger data clearly indicate that the $\mathrm{UO}_{2}(\sim 111)$ vicinal surfaces should be preferred 
over $\mathrm{UO}_{2}(\sim 100)$ vicinal surfaces for study of its catalysis as a function of surface crystallography. The modified LEED-Auger system has demonstrated a capability for handling reactant gases up to $10^{-3}$ torr pressure and, with the addition of a more nonreactive coating, the tantalum holder assembly should prove to meet all its design expectations.

Although the results obtained on $\mathrm{CoO}, \mathrm{Cr}_{2} \mathrm{O}_{3}$, and $\mathrm{UO}_{2}$ as regards their interaction with gases are surprisingly uneventful, there are definite directions that future research should take. First, the study of $\mathrm{Cr}_{2} \mathrm{O}_{3}$ has just begun and complete examination of its chemisorption properties, similar to that done with CoO, may yield positive results. Because of the great emphasis placed on the interaction of water with $\mathrm{Cr}_{2} \mathrm{O}_{3}$ during activation of the catalyst, ${ }^{28}$ very thorough investigation of its reactivity with $\mathrm{Cr}_{2}{ }_{3}(0001)$ is mandatory. Possibly this surface can be activated to hydrocarbon adsorption by the addition of water under the correct temperature and pressure conditions. Second, modifications should be made in the sample holder assembly to allow liquid nitrogen cooling of the sample. This would allow investigation of low-temperature adsorption as discussed at the conclusion of section IV. For this setup $\mathrm{UO}_{2}$, with its high electrical conductivity relative to $\mathrm{CoO}$ and $\mathrm{Cr}_{2} \mathrm{O}_{3}$, would allow the most latitude for experimental measurements. Third, experimental changes should be made to allow neutralization of surface charging using a second electron gun at an appropriate energy. This would immediately allow stable LEED-Auger measurements at and below room temperature on both $\mathrm{CoO}$ and $\mathrm{Cr}_{2} \mathrm{O}_{3}$.

\section{REFERENCES}

1. P. J. Estrup and E. G. McRae, "Surface Studies By Electron Diffraction," Surf. Sci. 25, 1-52 (1971).

2. C. C. Chang, "Auger Electron Spectroscopy," Surf. Sci. 25, 53-79 (1971).

3. D. P. Smith, "Analysis of Surface Composition with Low-Energy Backscattered Ions," Surf. Sci. 25, 171-191 (1971).

4. C. R. Brundle, "The Application of Electron Spectroscopy to Surface Studies," J. Vac. Sci. Technol. 11, 212-223 (1974).

5. R. W. Joyner, B. Lang, and G. A. Somorjai, "Low Pressure Studies of Dehydrocyclization of $\mathrm{n}$-Heptane on Platinum Crystal Surfaces Using Mass Spectrometry, Auger Electron Spectroscopy, and Low Energy Electron Diffraction," J. Catal. 27, 405-415 (1972). 
6. G. A. Somorjai and D. W. Blakely, "Mechanism of Catalysis of Hydrocarbon Reactions By Platinum Surfaces," Nature 258, 580-583 (1975).

7. D. W. Blakely and G. A. Somorjai, "The Dehydrogenation and Hydrogeno:ysis of Cyclohexane and Cyclohexene on Stepped (High Miller Index) Platinum Surfaces," T. Catal. 42, 181-196 (1976).

8. D. W. Blakely and G. A. Somorjai, "The Stability and Structure of High Miller Index Platinum Crystal Surfaces in Vacuum and in the Presence of Adsorbed Carbon and Oxygen," Surf. Sci. 65, 419-442 (1977).

9. D. R. Kahn, E. E. Petersen, and G. A. Somorjai, "The Hydrogenolysis of Cyclopropane on a Platinum Stepped Single Crystal at Atmospheric Pressure," J. Catal. 34, 294-306 (1974).

10. D. W. Blakely, E. I. Kozak, B. A. Sexton, and G. A. Somorjai, "New Instrumentation and Techniques to Monitor Chemical Surface Reactions on Single Crystals over a Wide Pressure Range $\left(10^{-8}-10^{5}\right.$ Torr) in the Same Apparatus," J. Vac. Sci. Technol. 13, 1091-1096 (1976) .

11. B. A. Sexton and G. A. Somorjai, "The Hydrogenation of $\mathrm{CO}$ and $\mathrm{CO}_{2}$ over Polycrystalline Rhodium: Correlation of Surface Composition, Kinetics and Product Distributions," J. Catal. 46, 167-189 (1977).

12. H. Hopster, H. Ibach, and G. Comsa, "Catalytic Oxidation of Carbon Monoxide on Stepped Platinum (111) Surfaces," J. Catal. 46, 37-48 (1977).

13. W. P. E11is and R. L. Schwoebe1, "LEED from Surface Steps on $\mathrm{UO}_{2}$ Single Crystals," Surf. Sci. 11, 82-98 (1968).

14. W. P. Ellis, "LEED Studies of $\mathrm{UO}_{2}(\sim 111)$ Vicinal Surfaces," Surf. Sci. 45, 569-584 (1974).

15. B. D. Campbe11 and W. P. Ellis, "Laser Simulation of LEED Patterns," Surf. Sci. 10, 124-127(1968).

16. W. P. Ellis, "Low Energy Electron Diffraction (LEED)," in Optical Transforms, H. S. Lipson Ed. (Academic Press, New York 1972), pp. 229-265.

17. P. M. Marcus, J. E. Demuth, and D. W. Jepsen, "Determination of the Structure of Ordered Adsorbed Layers by Analysis of LEED Spectra," Surf. Sci. 53, 501-522 (1975).

18. M. Henzler, "LEED-Investigation of Step Arrays on Cleaved Germanium (111) Surfaces," Surf. Sci. 19, 159-171 (1970).

19. W. P. E1lis, "Low-Energy Electron Diffraction Studies of Uranium Dioxide," J. Chem. Phys. 48, 5695-5701 (1968).

20. Aithough we concluded that the study of $\mathrm{ThO}_{2}(\sim 111)$ vicinal surfaces did not merit reporting separately, we include the results here because of the relevant comparison with $\mathrm{UO}_{2}$. 
21. T. N. Taylor, C. A. Colmenares, R. L. Smith, and G. A. Somorjai, "The Thorium (100) Crystal Face. A Study of Its Cleaning, Surface Structure, and Interaction with Oxygen and Carbon Monoxide," Surf. Sci. 5ít, 317-339 (1976).

22. J. L. Gland and G. A. Somorja1, "Low Energy Electron Diffraction and Work Function Studies of Benzene, Naphthalene and Pyridine Adsorbed on Pt(111) and Pt(100) Single Crystal Surfaces," Surf. Sci. 38, 157-186 (1973).

23. R. L. Burwe11.Jr., "Heterogeneous Catalysis," in Catalysis; Progress in Research, F. Basolo and R. L. Burwell Jr., Eds. (Plenum Press, New York, 1973), 51-74.

24. G. K. Wertheim and S. Hüner, "X-ray Photoemission Band Structure of Some Transition-Metal Oxides," Phys. Rev. Lett. 28, 1028-1031 (1972).

25. K. S. Kim, "X-ray-photoelectron Spectroscopic Studies of the Electron Structure of CoO," Phys. Rev. B 11, 2177-2185 (1975).

26. N. S. McIntyre and M. G. Cook, "X-ray Photoelectron Studies on Some Oxides and Hydroxides of Cobalt, Nickel, and Copper," Anal. Chem. 47, 2208-2213 (1975).

27. E. A. Bakulin, M. M. Bredov, and V. A. Vasil'ev, "Formation of the Electron Energy-Loss Spectra in Iron, Cobalt, and Nickel," Soviet Physics-Solid State 13, 3114-3115 (1972).

28. R. L. Burwe11, Jr., G. L. Haller, K. C. Taylor, and J. F. Read, "Chemisorptive and Catalytic Behavior of Chromia," Advan. Catal. 20, 1-96 (1969).

29. R. W. G. Wyckoff, Crystal Structures (John Wiley and Sons, Inc., New York, 1964), Vol. 2, pp. 6-8.

30. F. S. Galasso, Structure and Properties of Inorganic Solids (Pergamon Press, New York, 1970), pp. $235-239$.

31. H. W. Nelson and R. L. Carmichael, "Potential Nonnnuclear Uses for Depleted Uranium," AEC and Battelle Memorial Inst. report TID-8203 (January 1960).

32. J. C. Bresee, "Nonnuclear Uses for Depleted Uranium," Oık Ridge National Laboratory report ORNL-2889 (March 1960).

33. "Development of Depleted-Uranium Catalysts for Destruction of Air Pollutants in Automobile Exhaust," U. S. AEC and U. S. Bureau of Mines report TID-8213 (January 1963).

34. L. J. E. Hofer and R. B. Anderson, "Method of Treating Exhaust Gases with Urania-Containing Catalysts," U. S. Patent 3,140,148, July 7, 1964.

35. F. Nozaki and I. Inami, "Catalytic Selectivity of Uranium Oxide Catalyst for Dehydrogenation and Dehydration of Ethanol," Nippon Kagaku Kaishi No. 11, 2202-2204 (1972). 
36. V. S. Badik, Yu. A. Lyubchenko, A. N. Sergeeva, and L. M. Dmitrenko. "Activity and Thermal Stability of Precipitated Iron Catalysts for Ammonia Synthesis, Promoted with Uranium Oxides," Zhurnal Prikladnoi Khimii 47, 22392241 (1974) (English translation).

37. C. A. Colmenares, Lawrence Livermore Laboratory, private communication, (1976).

38. R. Bastasz and C. Colmenares, "Bibliography -- Catalytic Uses of Thorium and Uranium," Lawrence Livermore Laboratory report UCID-17499 (June 1977).

39. T. Matsushima and J. M. White, "Thermal Decomposition of Methanol Adsorbed on Alumina," J. Catal. 44, 183-196 (1976).

40. D. C. Foyt and J. M. White, "Thermal Decomposition of Methanol Adsorbed on Magnesia," J. Catal. 47, 260-268 (1977).

41. W. Dianis and J. E. Lester, "A Study of Nitric Oxide Adsorbed on Nickel Oxide, Cobalt Oxide, and Graphite by X-ray Photoelectzon Spectroscopy," Surf. Sci. 43, 602-616 (1974). 